\title{
Analysis of the Effectiveness of Coffee Cooperatives in Coffee Value Chain in Melka-ballo Woreda, East Hararghe Zone, Oromia Regional State, Ethiopia
}

\author{
Ahmed Aliyi \\ Dire Dawa University, College Of Business and Economics, Department of Management
}

\begin{abstract}
This study was aimed at analyzing the effectiveness of coffee value chain in Melka-ballo woreda of Oromia Region with specific objectives of identifying actors in the coffee value chain and describing their roles; examining the linkages between cooperatives and other actors in the coffee value chain; and analyzing determining factors affecting coffee cooperatives in creating effective value chain. The study was conducted on three primary coffee cooperatives by selecting 291 member respondents by using multi-stage sampling technique. Data were collected from both primary and secondary sources. Primary data was collected using semi-structured questionnaire. The collected data were analyzed by using descriptive statistics like percentage and frequency, three level likert scale and binary logistic regression. The result of the descriptive statistics showed that in the study area there are two types of actors namely, direct/primary and indirect/supportive actors and most of them perform more than one role in the value chain. The result also indicated that there are five types of linkages between actors namely; Horizontal linkage, Vertical linkage, Technical Support Linkage, Business linkage and Marketing Linkage. The opinion of the respondents showed that the linkage among actors in the coffee value chain was weak. Moreover, the result of binary logistic regression revealed that corruption, Training, and management capacity has statistically significant partial effect on the effectiveness of coffee cooperatives in coffee value chain at $p$-value less than 0.01 whereas access to credit, technology and proximity to cooperatives has statistically significant partial effect on the effectiveness of cooperatives in coffee value chain at p-value less than 0.05 . Accordingly, access to credit, training and management capacity has statistically significant positive effect on the effectiveness coffee cooperatives in coffee value chain whereas corruption, technology and proximity to cooperative society has statistically significant negative effect on dependent variable "effectiveness of coffee value chain". It was recommended that greater attention should be given by all stakeholders and actors in the coffee value chain to design strategies on how to smooth their relationship and avoid any bottlenecks such as corruption, inefficient management and poor quality training and designing simple and cheap technology. Sufficient and interest free credit facilities should be available in a timely manner to cooperative members and strategies should be designed to link microfinance with the cooperatives.
\end{abstract}

Keywords: Coffee cooperative, Ethiopia, Effectiveness, Linkage, Value chain

DOI: $10.7176 / \mathrm{EJBM} / 11-7-02$

Publication date:March $31^{\text {st }} 2019$

\section{PART ONE}

\section{INTRODUCTION}

\subsection{Background of the study}

Agriculture remains the backbone of the economy of most developing countries. Typically, it is the largest source of employment; often two-thirds or more of the population are dependent for its livelihood on farming. The laborintensive character of the sector reduces its contribution to the gross domestic product, but its contribution nevertheless ranges between 20 and 60 percent in most developing countries. Agricultural exports are the principal sources of foreign exchange earnings for most developing countries (Warren C. and Strokes M., 1985, cited in Demeke, 2007).

World trade in agricultural products has been growing especially in the 1990s. In 2001, the total nominal value of world agricultural trade was US\$412 billion, compared with US\$326 billion in 1990 and US\$234 billion in 1980. In addition, there is a breakdown between developed and developing countries. Developed countries account for approximately $70 \%$ of the agricultural trade although the share has been falling over the past decade (JICA, 2005, cited in Demeke, 2007).

Ethiopia is an agrarian country and agriculture accounts for 54 percent of the domestic product (GDP) and agriculture employs about 80 percent of the population and accounts for about 90 percent of the exports (CSA, 2000, cited in Demeke, 2007).

Coffee is one of the most important commodities in the world economy, next to oil. South America, South East Asia and Africa took the first three positions according to their order of production. The production of this commodity varies across regions. Coffee particularly is the backbone of the economy of Ethiopia. Coffee has always been the Ethiopian most important cash crop and largest export commodity, which account 90 percent of 
exports and 80 percent of total employment. By its very nature, coffee is highly labor-intensive production activities. Thus very significant part of the population derives its livelihood from coffee. Coffee thus has a significant impact on the socio-economic life of the people and economic development of the country (ECEX, 2008). According to World Bank (2009), Coffee production in Ethiopia is the driving force since over a million coffee farming households and about $25 \%$ of the total population of the country is dependent on production, processing, distribution \& export of coffee.

Ethiopia produces around $4 \%$ of world production and more than $30 \%$ of the total production in Sub-Sahara Africa (MoARD, 2009). Although the country is world coffee producer, the small coffee producers were unable to get significant benefit from their product. The main reason for this, among others is lack of empowerment of the producers over their product and unbalanced linkage between producer and other coffee actors like private coffee exporters and middle men in the coffee value chain. In addition, absence of strong organization representing coffee producers in the market is also another factor holding back the coffee growers (M.Karthikeyan, 2015). Unstable markets, the paucity of information; low social and economic status, and etc., are also other problems of coffee marketing. The farmers also linked to actors who have more resources, information, and options and more economically powerful organizations in coffee value chain (Demeke, 2007). Actors are those individuals, organizations and all stakeholders who participate in the transfer and change the normal state of coffee directly or indirectly from one to another until the product reach final consumers.

Intervention to reduce uncertainty and other marketing problems and to bring the peasant households into profit maximizing category may be realized through establishment of rural institutions, such as cooperatives (Demeke, 2007). In 1995, the International Co-operative Alliance (ICA), the apex organization that represents cooperatives worldwide, defined a cooperative as: An autonomous association of persons united voluntarily to meet their common economic, social and cultural needs and aspirations through a jointly owned and democratically controlled enterprise. At present, there are 56,044 organized primary and 307 secondary cooperatives, and the total number of members in primary cooperatives reached 9.2 million owning birr 8.80 billion capital (FCA, 2014).

It is evident that the cooperatives are playing a great role in the local and international trade of the country. These cooperatives, on behalf of their members, are able to reach and inter in to far markets. Due to this, many coffee growers have changed their life. However, due to dramatic change of the world coffee market the long lasting change of the life of the producers fall under question mark. In the area where this study has been conducted coffee is marketed by both under individual traders and coffee marketing cooperatives. However, the issue of value addition was forgotten by almost all actors in the coffee chain. Actors are those individuals and organizations who participate in the transfer of coffee directly or indirectly from one to another until the product reaches final consumers. To compete in the stiff competition of the world coffee market and protect the market position they already have and fetch their members with good return on their product value addition became choice less activity for coffee cooperatives. This can be achieved by building effective chain in which every actor benefit according to their participation in the chain. Thus, this study was aimed at assessing the effectiveness of coffee cooperatives in coffee value chain.

\subsection{Statement of the Problem}

The coffee market pass through long chain involving many actors like producers, local collectors, retailers, wholesalers, exporters and users. This resulted in different problems like delayed payment, lack of market information, and lack/less of awareness of the market to whom and to what price they have to sale their products. These and others together resulted in dramatic fall in the producers' share of market price. These practices have continued for a long period in coffee producer's area and leading them to eradicating coffee production and substituting it with a less productive cash crop mostly, khat (jima).

The government of Ethiopia recognized the seriousness of the problem and permitted coffee cooperatives to sell members' product directly to foreign market without any interference of middlemen like private wholesalers and exporters.

However, although these cooperatives could able to shorten the long chain of the coffee market, they are facing several problems in adding value to member's produces. Among these problems the most challenging in the study area as understood from FGD discussion with management committee are the following;

- Majority of the cooperative members have a minimum awareness regarding to coffee value chain.

- Inadequate knowledge and skills on quality coffee production systems among value chain actors.

- $\quad$ Poor coffee processing procedure that created higher costs and reduced the quality of the beans reaching the markets and others.

- Hence, no attention is given in creating linkage between actors.

Due to these problems and others, coffee producers suffered from poor returns on their produces. To have successful coffee cooperatives, it is essential to examine the Coffee Value Chain of existing cooperatives and draw practical solution to critical constraints. To accomplish such important task, empirical studies have paramount importance in areas of coffee value chain. However, irrespective of the problem that Ethiopian coffee producers 
are facing, the study conducted on the subject specially in Ethiopia, is insignificant. Although some researchers conducted study on coffee producers in the country, they mostly focus on market problem rather than the paramount problem of coffee producers in the country- that's whether the path of coffee from producers to market/users is effective or not (i.e. coffee value chain). Only M. Karthikeyan (2015) of Ambo University came out with rough essay on the effectiveness of coffee value chain in Sasiga District of Oromia Region. Although he tried to express the linkage between actors of coffee value chain, he failed to identify some dominating actors like coffee seedling nurseries (which feed coffee growers with improved coffee seedlings), contrabandists (which play paramount role in deteriorating the quality of Harar coffee by mixing with low quality and cheep coffee from western part of Ethiopia), Coffee Standard and Quality Inspection Center (which has a power to inspect and pass or fail the coffee before it brought to central market) and financial institutions like Oromia Cooperative Bank (which is the immediate financial sources of coffee cooperatives), and their roles they play in the chain. More important, he considered only direct relationship (the influence of primary actors) by ignoring the indirect relationship (the influence of Supportive actors) exists between actors in the chain. The representativeness of the sample is also under question. Because, he simply used the estimates of the proportion of population to be $10 \%$ $(\mathrm{p}=0.1$ and $\mathrm{q}=0.9)$.

So, this study was aimed at examining the Effectiveness of the coffee Cooperatives in Coffee Value Chain in Melka-ballo woreda in general and specifically to answer the following basic questions;

- Who are actors in the coffee value chain and what are the roles they play in the chain?

- What types of linkages do exist between coffee cooperatives and other actors in coffee value chain?

- What is the degree of strength of the linkages between coffee value chain actors?

- What are the determining factors that affect the effectiveness of coffee value chain?

\subsection{Objectives of the study}

\subsubsection{General Objective of the Study}

The general objective of this study was to investigate the effectiveness of coffee cooperatives in coffee value chain in Malka-ballo woreda, Oromia Region.

\subsubsection{Specific objectives}

1. To identify actors in the coffee value chain and describe their roles.

2. To investigate the linkages between cooperatives and other actors in the coffee value chain.

3. To examine the degree of strength of the linkages between actors existing in the chain.

4. To analyze determining factors affecting the effectiveness of coffee value chain.

\subsection{Significance of the study}

The empirical information that was generated by this study would have a paramount important. It would be useful for the management bodies of coffee cooperatives under consideration in improving their effectiveness in coffee value chain through appropriate and relevant measures. It would enable actors of the value chain working together to develop synergies to ensure the long-term growth and prosperity of the coffee industry in general and coffee producers in particular. This study would be a good stepping stone for other researchers who interested in studies on this and related title/field. In brief, this research would be useful to cooperative societies, researchers, and governmental and non-governmental organizations for planning and development of coffee cooperatives in the study area as well as in the country.

\subsection{Scope and limitations of the study}

This study was geographically delimited to only Melka-ballo woreda. It was also delimited to identify actors in the coffee value chain, and to examine the linkages between cooperatives and other actors and to analyze determining factors affecting the effectiveness of cooperatives in coffee value chain. The coverage of the study was also limited only to three primary coffee cooperatives in Melka-ballo woreda and therefore, comprehensive results would not be generalized to other area.

\subsection{Organization of the study}

This thesis is organized into five parts. The first part deals with background, Statement of the problem, objectives, research questions, significance, limitation and scope of the study and organization of the thesis. The second part focuses on review of literatures and conceptual framework of the study. Whereas part three describes the research methodology and operational definition of dependent and independent variables. Part four focuses on results of the study and the last part presents summary, conclusion, and recommendations of the study.

\section{PART TWO}

REVIEW OF RELATED LITERATURE

In this part of the study the basic concepts of value chain, Value chain analysis, Value Chain Approach in Ethiopia, 
Coffee value chain, Cooperative Unions and Association of Primary Cooperative Societies, Value chain actors, Value addition and empirical reviews would be discussed. Lastly, Conceptual Framework of the Study was designed from reviewed literature.

\subsection{Definitions and Concepts of Value Chain}

According to Abraham (2013), industry chains are classified as either 'supply' or 'value' chains. The following definitions within the general term 'industry chain' are used:

Supply chain: It mean the physical flow of goods that are required for raw materials to be transformed into finished products. Supply chain management is about making the chain as efficient as possible through better flow scheduling and resource use, improving quality control throughout the chain, reducing the risk associated with food safety and contamination, and decreasing the agricultural industry's response to changes in consumer demand for food attributes (Dunne, 2001, as cited in Abraham, 2013).

Value chain: It mean a group of companies working together to satisfy market demands. It involves a chain of activities that are associated with adding value to a product through the production and distribution processes of each activity (Schmitz, 2005). An organization's competitive advantage is based on their product's value chain. The goal of the company is to deliver maximum value to the end user for the least possible total cost to the company, thereby maximizing profit (Porter, 1985).

A value chain is the full range of activities required to bring a product from conception, through the different phases of production and transformation. A value chain is made up of a series of actors (or stakeholders) from input suppliers, producers and processors, to exporters and buyers engaged in the activities required to bring agricultural product from its conception to its end use (Kaplinsky and Morris, 2001). Bammann (2007) has identified three important levels of value chain;

* Value chain actors: The chain of actors who directly deal with the products, i.e. produce, process, trade and own them.

* Value chain supporters: The services provided by various actors who never directly deal with the product, but whose services add value to the product.

* Value chain influencers: The regulatory framework, policies, infrastructures, etc.

The value chain concept entails the addition of value as the product progresses from input suppliers to producers and consumers. A value chain, therefore, incorporates productive transformation and value addition at each stage of the value chain. At each stage in the value chain, the product changes hands through chain actors, transaction costs are incurred, and generally, some form of value is added. Value addition results from diverse activities including bulking, cleaning, grading, and packaging, transporting, storing and processing (Anandajayasekeram and Berhanu, 2009) as shown in figure 1 for the case of a typical agricultural value chain.

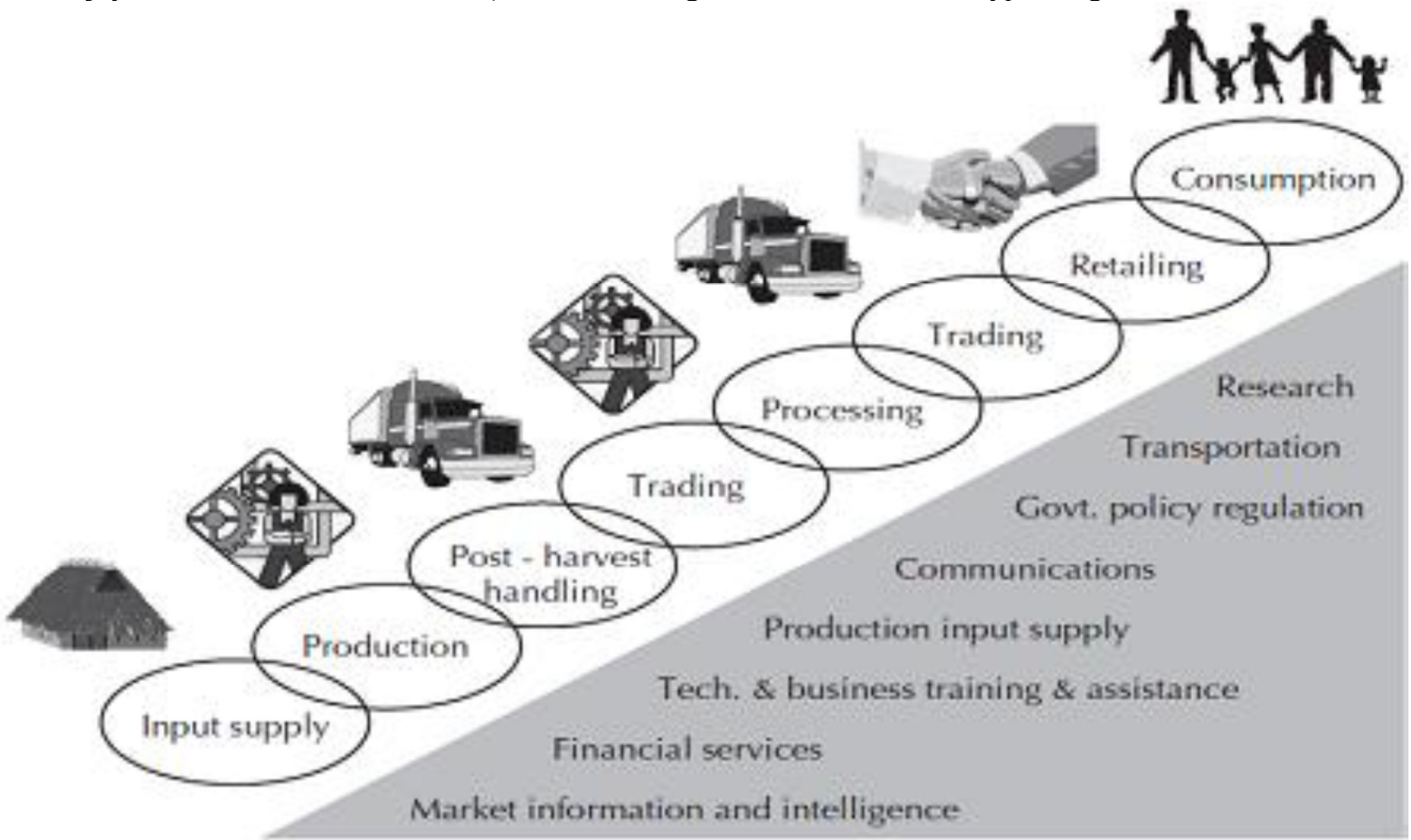

Figure 1: Typical agricultural value chain and associated business development services Source: Adapted from Anandajayasekeram and Berhanu (2009).

Value chains encompass a set of interdependent organizations, and associated institutions, resources, actors 
and activities involved in input supply, production, processing, and distribution of a commodity. In other words, a value chain can be viewed as a set of actors and activities, and organizations and the rules governing those activities.

Value chain management is about creating the added value at each link in the chain and a sustainable competitive advantage for the businesses in the chain. How value is actually created is a major concern for most businesses. Porter (1985) indicated that value can be created by differentiation along every step of the value chain, through activities resulting in products and services that lower buyers' costs or raise buyers' performance. In much of the food production and distribution value chain, the value creation process has focused on commodities with relatively generic characteristics, creating relatively small profit margins.

The value chain approach is developed by Michael Porter in the 1980s in his book "Competitive Advantage: Creating and Sustaining Superior Performance". According to Porter, a value chain "disaggregates a firm into its strategically relevant activities in order to understand the behavior of costs and potential sources of differentiation". This value chain allows to diagnose the competitive advantage of a firm or industry and to enhance this advantage by tailoring the value chain (Porter, 1985).

The value chain framework of Porter is "an interdependent system/network of activities connected by linkages". When the system is managed carefully, the linkages can be a vital source of competitive advantage. The value chain analysis essentially entails the linkage of two areas. First the value chain links the value of the organizations' activities with its main functional parts then the assessment of the contribution of each part in the overall added value of the business is made. In a more contemporary sense, Kaplinsky and Morris, (2001) defined a 'simple' value chain as the description of a full range of activities necessary to carry a product or service from conception, through the various production stages, distribution to the final consumer, and removal after its use which is implemented by various actors (producers, processors, traders, service providers, etc). Nonetheless, in real life applications, value chains tend to be more complex, involving several producers, creating manifold links within the value chain. Therefore it can appear that one value chain may be composed of several smaller value chains.

Value chain analysis often uses methods such as value chain diagrams to visualize chains and locate the actors, margins, relationships, stakeholders/ supporters and shape of a chain in order to reveal information about some of these important measures of chain quality (Kaplinsky and Morris, 2001). Porter utilized the framework of value chains to assess how a firm should position itself in the market and in relation to suppliers, buyers and competitors. A visual representation of different aspects of value chain is represented in figure 2 below;

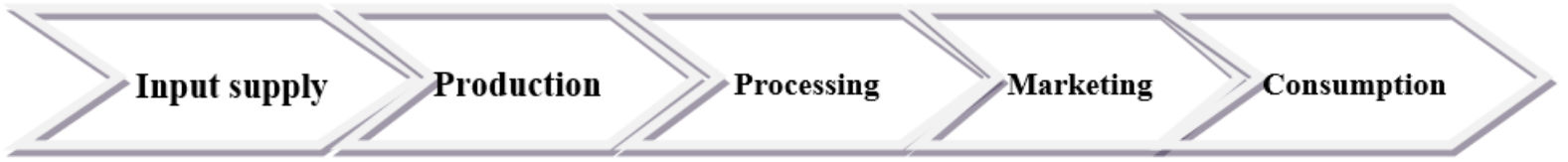

Figure 2: diagrammatic representation of porter's value chain

Source: Value Chain Adapted from GTZ, 2004a as cited in Schipmann, 2006,p 13

\subsection{Value Chain Analysis}

Value chain analysis (VCA), or commodity chain analysis, disaggregates the global structure of fabrication, trade and consumption of commodities and allows for the identification of actors and geographical divisions (Tuvhag, 2008). Firstly, at its most basic level, a VCA systematically maps the actors participating in the production, distribution, marketing and sales of a particular product (or products). This mapping assesses the characteristics of actors, profit and cost structures, and flows of goods throughout the chain, as well as employment characteristics and the destination and volumes of domestic and foreign sales (Kaplinsky and Morris 2001). Such details can be gathered from a combination of primary survey work, focus groups, informal interviews and secondary data.

Secondly, VCA can play a key role in identifying the distribution of benefits to different actors in the chain. That is, through the analysis of margins and profits within the chain, one can determine who benefits from participation in the chain and which actors could benefit from increased support or organization. This is particularly important in the context of developing countries (and agriculture in particular), given concerns that the poor are particularly vulnerable to the process of globalization (Kaplinsky and Morris, 2001). One can supplement this analysis by determining the nature of participation within the chain to understand the characteristics of its participants. A number of factors explain the distribution of benefits between actors; the VCA focuses on the dynamics of rent, and thereby transcends different economic branches and sectors.

Through a full view of the whole chain, the "rent-rich activities" can be traced with greater ease. Besides, the global focus of VCA accounts for the global dynamics of returns, not only on a national level. This allows for the identification of opportunities to increase income more accurately than analysis at a purely national level would (Kaplinsky and Morris, 2000).

Thirdly, VCA can be used to examine the role of upgrading within the chain. Upgrading can involve improvements in quality and product design that enable producers to gain higher value, or through diversification 
in the product lines served. An analysis of the upgrading process includes an assessment of the profitability of actors within the chain as well as information on current constraints. Governance issues play a key role in defining how such upgrading occurs. In addition, the structure of regulations, entry barriers, trade restrictions and standards can further shape and influence the environment in which upgrading could take place.

Finally, VCA can highlight the role of governance in the value chain. Governance in a value chain refers to the structure of relationships and coordination mechanisms that exist between its various actors. Governance is important from a policy perspective for identifying the institutional arrangements that may need to be targeted to improve capabilities in the value chain, remedy distributional distortions, and increase value added in the sector. Here a distinction is made between two types of governance: those cases where the coordination is undertaken by buyers ('buyer-driven commodity chains') and those in which producers play the key role ('producer-driven commodity chains').

According to Bayrau, A., et al, (2010), value chains are forms of industrial organization that involve institutional arrangements that link producers, processors, marketers and distributors. It is the mechanism of getting products from sellers (in our case small scale coffee producers) to buyers, who are separated by time and space. This mechanism progressively adds and accumulates the value of the products as they pass from one member of the chain to the next. In this institutional arrangement, commodities, information and technology move and flow from one agent of the chain to another.

Value chain analysis is an approach that takes into account the entire chain of sequence of productive (meaning value-added) activities starting from the design, leading to and supporting end use (Sturgeon, 2001). It examines the performance of each economic agent at each stage of the chain rather than concentrating on just one level of activity. The analysis helps to determine the competitive advantage of actors in the entire commodity chain. This makes the analysis more systemic and comprehensive by covering the entire gamut of activities involved and the corresponding types of governance involved.

Value chain analysis has three key elements: (a) barriers to entry and rent, (b) governance, and (c) systemic efficiency (as opposed to point efficiency, meaning that the links of the complex value chain need to be integrated to make them efficient) (Kaplinsky 2000).

\subsection{Production chain/Supply chain/ Market chains versus Value Chains}

The terms production chain, supply chain, market chain and value chain are often used interchangeably, but in fact there are some important differences (Table 1). In its simplest definition, the terms production chain, supply chain, market chain are synonymously used to describe all participants involved in an economic activity which uses inputs and services to enable a product to be made and delivered to a final consumer. A value chain is understood as a strategic network between a numbers of independent business organizations. According to Hobbs et al. (2000), a value chain is differentiated from a production/supply chain because participants in the value chain have a longterm strategic vision, disposed to work together, oriented by demand and not by supply, shared commitment to control product quality and have a high level of confidence in one another that allows greater security in business and facilitates the development of common goals and objectives.

Table 1: production/supply/market chain versus value chain

\begin{tabular}{|l|l|l|}
\hline Factors & Production/supply/ market chain & Value market chain \\
\hline Information flow & Little or none & Extensive \\
\hline Principal focus & Cost / price & Value / quality \\
\hline Strategy & Basic product (commodity) & Differentiated product \\
\hline Orientation & Led by supply & Led by demand \\
\hline Organizational structure & Independent actors & Independent actors \\
\hline Philosophy & Competitiveness of the enterprise & Competitiveness of the market chain \\
\hline
\end{tabular}

Source: Hobbs et al. (2000).

The goal of a value chain is to optimize performance in that industry using the combined expertise and abilities of the members of the chain. Successful chains depend on integration, coordination, communication and cooperation between partners with the traditional measure of success being the return on investment (Dunne, 2001; Bryceson and Kandampully, 2004).

\subsection{Value Chain Approach in Ethiopia}

The literature on value chain indicates that there are two distinct types of international economic networks, "producer-driven" and "buyer-driven" global commodity chains. These feature the type and intensity of competition that one can observe across different industries. (Gereffi, 1999). "Producer-driven" commodity chains are those chains of technology and capital intensive industries, where the producers are the leaders in the chain 'in coordinating production networks'. Such commodity value chain, include industries such as automobiles, air craft, computers, semiconductors and heavy machinery" (Gereffi, 1999:1). On the other hand, buyer-driven commodity chains refer to those industries in which lead firms "happen to be large retailers, marketers, and branded 
manufacturers, which play the pivotal roles in setting up decentralized production networks in variety of exporting countries, typically located in the third world. This pattern of trade-led production has become common in laborintensive, consumer goods industries such as many agricultural commodities, garments, footwear, toys, house wares, consumer electronics, and a variety of handcrafts".

"Profits in buyer-driven chains are derived not from scale, volume, and technological advances as in producer-driven chains, but rather from unique combinations of high-value research, design, sales, marketing and financial services that allow the retailers, designers, and marketers to act as strategic brokers in linking overseas factories and traders with evolving product niches in their main consumer markets" (Gereffi, 1999: 1-2).

The value chain of the Ethiopian small scale farmer production and marketing system appears to fit into the buyer-driven type chains. While retailing and marketing appears to be more concentrated, agricultural production is scattered across the country involving millions of small scale farmers, largely producing for self-subsistence. The value chain of Ethiopian agricultural products, involve millions of small scale farmers against a few different types of retailers. The retailers have clear advantage over the small scale farmer, in terms of access to modern infrastructure, proximity to market, management capacity, access to market information as well as access to capital (Bayrau, A., et al., 2010).

Kindie, Shahidur and Solomon, (2010), also noted that there are many actors between the producers and the consumers, all performing various activities at different scales of operation, a model that can indicate inefficiencies in the value chain. For instance, a recent study found that a typical trader in Ethiopia operates within a radius of only 64 kilometers, suggesting that grains change many hands before reaching consumers, as grain often travels much further than 64 kilometers to consumers. The large number of players along the value chain, and the fact that traders operate within a small radius, has important implications for marketing efficiency. It implies that spatial arbitrage takes place depending on personal relationships (or social capital), limiting long distance trade and increasing the price that consumers pay. According to this study, although there are several actors between the producers and the consumers who change agricultural products many hands within short radius of market, there number relative to large small scale farmers is very low. Because of such differences in economic capacity, there is power asymmetry across the value chain of Ethiopia. The retailers have more market power over the Ethiopian small scale farmer which is reflected in terms of decision making on prices, and the share of marketing margin going to each group.

There are additional factors that undermine the marketing power of Ethiopian small scale farmers. The tax obligation of the small scale farmer matures immediately after the harvest period. In addition to this, the post harvest season is the off-season in the agricultural system in which the farmer encounters social and religious obligations, demanding substantial expenditures. Moreover, previous credits are expected to be served during the post-harvest period, adding to the problem. These factors force the farmers to sell large parts of their marketing surplus during the first two months after harvesting (Kindie, Shahidur and Solomon, 2010, 2010).

Yet, according to (Kindie, Shahidur and Solomon, 2010), there are no financial or other types of instruments that help alleviate the temporary cash shortage of the small scale farmers. Though, there are recent interventions that promote micro-financing arrangements they are yet at their infancy to be able to deal with the problem. The higher cash requirements during the post-harvest period and the absence of instruments to address it coupled with lack of market information on prices, market trends, etc, leave the small scale farmer powerless in terms of decisions on price making and selling period (Kindie, Shahidur and Solomon, 2010). These factors compel the Ethiopian farmer to sell its small amounts of marketing surplus at low prices. The issue of securing a fair share of the final prices going towards the farmers requires addressing these underlying problems, which are beyond the scope of one institution.

Like any other commodity, the value chains of agricultural commodities involve different activities. These activities include mobilization of the necessary agricultural inputs, chemicals, and rainfall/irrigation/, improved seeds/nursery/, labor and land management. The activities also involve the planting and the management of a given farm. There are also post-harvest activities of preparing the product and making it ready for transport and delivery to the buyer.

A typical small scale farmer may have three sales outlets for his/her marketable surplus. One is supplying directly to agro processing industries, which is a desired approach because the value addition and the economic benefits from such vertical integrated agro-processing industry is substantial. The other outlet is domestic sales to urban centers, which is expected to grow with increase of the rate of urbanization, an increase in income and population, and other demand enhancing factors. The third sales outlet is export, which may involve multiple chains and agents.

\subsection{Benefit of Value Chain in Agricultural Sector in Ethiopia}

Value chain is useful as a poverty-reduction tool if it leads to increase on and off farm rural employment and income. Increased agricultural productivity alone is not a sufficient route out of poverty within a context of globalization and increasing natural resource degradation. A focus on post-harvest activities, differentiated value 
added products and increasing links with access to markets for goods produced by low-income producers would appear to be the strategy open to smallholders (Lundy et al., 2002).

Traditionally, little attention has been paid to the value chains by which agricultural products reach final consumers and to the intrinsic potential of such chains to generate value added and employment opportunities. While high-income countries add nearly US\$185 of value by processing one tone of agricultural products, developing countries add approximately US\$40. Furthermore, while 98 percent of agricultural production in highincome countries undergoes industrial processing, barely 38 percent is processed in developing countries. These indicate that well developed agro-value chains can utilize the full potential of the agricultural sector (UNIDO, 2009).

In the process of preparing an agro-industrial master plan for Ethiopia, a prioritization process was conducted for several commodities to identify those offering the highest prospects for growth (UNIDO and FAO, 2009). Group 1: Commodities that are highly important to the economy due to the large population involved in their production and to their contribution to national food security. This group includes: (i) cereals (wheat, maize, teff and barley); (ii) oilseeds (sesame, Niger seed, linseed and rapeseed); (iii) coffee; and (iv) sugar. Group 2: Commodities that are of importance to the economy, due to the number of people involved in production, processing and marketing as well as to their contribution to food security. This group includes: (i) dairy products; (ii) meat; (iii) tea; and (iv) fruit and vegetables. Group 3: Commodities that entail a competitive advantage for Ethiopia. This group includes: (i) honey; (ii) pulses; (iii) spices; and (iv) grapes/wine.

\subsection{Value Chain Actors}

Value chain actors are those involved in supplying inputs, producing, processing, marketing, and consuming agricultural products (Kindie, Shahidur and Solomon, 2010). They can be those that directly involved in the value chain (farmers, cooperatives, processors, traders, retailers, and consumers) or indirect actors who provide financial or non-financial support services, such as credit agencies, business service and government, researchers and extension agents. For instance, according to them, the maize value chain in Ethiopia involves multiple actors, including: input suppliers, producers, traders (local assemblers and wholesalers), retailers and processors, and consumers.

M.Karthikeyan (2015), also argued that actors involved in the coffee value chain are mainly concerned with technology generation, promotion, input supply, transport, provision of training, access to credit, and some other issues related to the value chain. According to him, agriculture and rural development office, private input suppliers, private coffee seed multiplier, producers (members of the cooperatives), primary coffee cooperatives, private traders (Sebsabis), cooperative unions, ECEX, and local users are identified as main actors currently involved in different intervention areas of the coffee value chain in Sasiga woreda of Oromia.

Another study also indicated that coffee supply chain connecting coffee producers and consumers in Ethiopia involves cooperatives, intermediary traders (small and large product collectors/ cooperatives), suppliers (those who deliver coffee to auction centers), processors, rosters, distributors, exporters, agents, importers, retailers and a lot of other actors (ECEX, 2008).

Birhanu, et al., (2013) also agreed that in Ethiopian coffee value chain, there are numerous participants which include smallholder coffee farmers or state farms, primary collectors, suppliers, processors, service cooperatives, unions, exporters and various governmental institutions.

\subsection{Coffee value chain}

There is no doubt that the starting and leveraging points for Ethiopian coffee sector development is the market. A comprehensive value chain approach to global marketing is an excellent framework to direct business development and market linkages. Equally important in understanding the potential growth of the coffee sector is that Ethiopia is one of the poorest countries in the world with literacy rates, roads per capita, manufacturing level, and overall competitive measures rated in all cases in the bottom 10 countries of the world. Additionally, both business knowledge and experience are extremely low as a result of years of economically disruptive war and Marxist rule preceded by essentially a feudal system. Ethiopia's ability to enter and be competitive in international markets is limited because of these factors (Kindie, Shahidur and Solomon, 2010).

Linking coffee producers to international markets in an economy such as Ethiopia's where many of the requisites to successful participation in global markets are so weak requires institutional and capacity building carefully provided to support value chain expansion. Building the institutions and capacity of the cooperative sector in the case of smallholder exports of specialty coffee is essential to opening a new coffee export channel. In Ethiopia for coffee cooperatives, the combination of value chain approach and strong institutional development interventions provided the basis for a success in coffee cooperatives. (ACDI/VOCA, 2006, cited in Demeke, 2007).

\subsubsection{From seed to sale}

The value chain in coffee production involves the following steps: 
- Nursery operations to produce seedlings;<smiles></smiles>

- farm-level operations (planting, weeding, fertilizing, pruning, spraying, picking/harvesting of red cherry);

- transportation of cherries to the pulpery/coffee factory;<smiles>C1=CC=C1</smiles>

- coffee factory primary processing: pulping, fermenting, washing and drying to produce parchment coffee, either at a cooperative facility or in a farm-based pulpery;

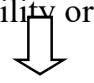

- curing operations (removing parchment/peeling, cleaning and polishing the beans to produce green coffee beans), by a miller;<smiles>c1ccccc1</smiles>

- milling plant operations: hulling, cleaning/polishing, sorting, grading, bagging, e.g. by Kenya Planters Cooperative Union (KPCU) and Thika Coffee Mills;

$$
\text { L }
$$

- auctioning at the Nairobi Coffee Exchange (NCE) where dealers, roasters, marketers and exporters buy various grades of green coffee;

- Roasting, grinding, blending and packing/packaging by roasters and marketing agents, e.g. C. Dorman's and Nairobi Java House. Can be done locally or in the importing country; and

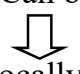

- Marketing and selling: locally, regionally, globally - packed or even in bulk - by dealers, roasters, marketers and exporters to supply coffee to consumers.

\subsection{Coffee Value Chain in Ethiopia}

A value chain is a supply chain consisting of the input suppliers, producers, processors and buyers that bring a product from its conception to its end use. In Ethiopia, coffee value chain approach to development seeks to address the major constraints at each level of the supply chain, rather than concentrating on just one group (e.g., producers) or on one geographical location. Constraints often include a lack of technical, business or financial support services, a difficult regulatory framework, poor public infrastructure (roads, telecommunications, electricity, etc.), a lack of information about or weak connections to end markets, and/or inadequate coordination between firms. Taking a value-chain approach is often essential to successful economic development since micro and small enterprises and smallholder farmers will only benefit over the long term if the industry as a whole is competitive (Jim, D., and Ruth C., 2006, P5-7).

\section{Ethiopian Coffee Value Chain}

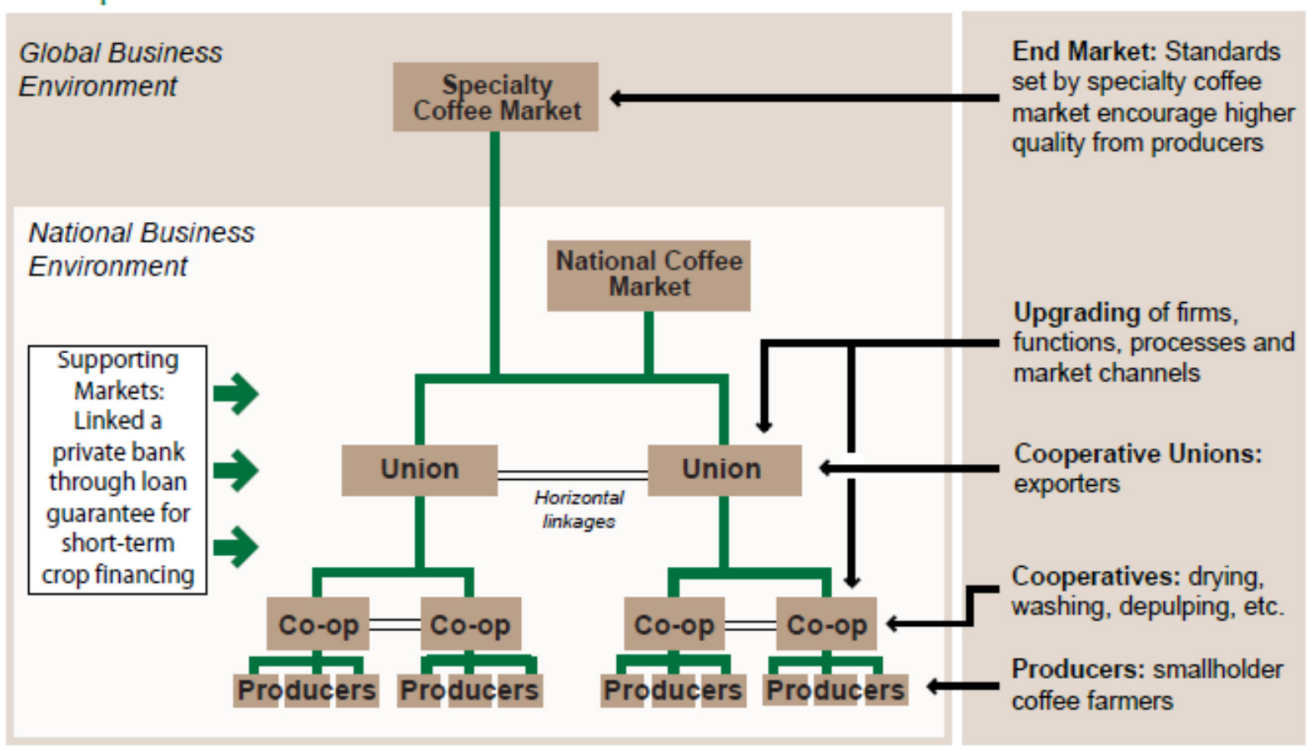

Figure 3: Ethiopian coffee value chain

Source: ACDI/VOCA report, (2006)

Literatures indicate that cooperative society's based Ethiopian coffee value chain was started in 2001, when the government of Ethiopia removed the requirement for cooperatives to sell all coffee through the national auction, opening the way for direct export sales. Figure 3 above shows that cooperative societies are the uncles of the value 
chain. ACDI/VOCA recognized the importance of this policy change, as well as the inability of the coffee cooperatives to take advantage of the reform, and developed and applied a value-chain approach (see text box at left) to address the constraints at each level of the industry (Jim, D., and Ruth C., 2006, P5-7). Within this overall approach, a particular emphasis was placed on strengthening the cooperation between small scale producers, as well as establishing secondary cooperatives or "unions" to achieve the economies of scale needed to reach international markets.

According to Jim, D., and Ruth C., (2006, P5-7), the value-chain framework developed by ACDI/VOCA (under the Accelerated Microenterprise Advancement Project-Business Development Services Indefinite Quantity Contract) addresses constraints and exploits opportunities in five areas: 1) the business enabling environment, 2) the end markets, 3) supporting markets, including finance, 4) firm-level upgrading and 5) interfirm cooperation.

\section{Business Enabling Environment}

The cooperative experience in international markets has demonstrated the importance of quality production traced to origin with substantial buyer monitoring and even involvement with coffee growers. The government now understands the need for change to grow the coffee export market. The success of the cooperatives in coffee exports since 2001, plus the pull of the growth in size and profitability of the international specialty coffee market are together creating the momentum for further marketing reforms.

\section{End Markets}

By conducting end-market analyses and proactively seeking out international specialty coffee buyers, the four coffee unions are strengthening their members' bargaining position in the international market place, returning a higher share of market price to producers and allowing farmers to achieve economies of scale and to take control of their economic future. Consequently, union exports have grown from 126 MT five years ago to 12,800 MT in 2005.

\section{Supporting Markets}

A constraint at both the cooperative and union levels has been the lack of financing. With USAID support, ACDI/VOCA attracted a private bank into a U.S. government loan guarantee mechanism, which in its first year made $\$ 680,000$ available in local currency to unions for the purchase of product from member cooperatives for later sale. Repayment rates have remained constant at 100 percent, and the program has since been expanded to include a second bank and cover medium-term loans for equipment and infrastructure investments with a new ceiling of $\$ 18$ million.

\section{Firm-level Upgrading}

Through technical assistance from staff, consultants and volunteers - including several highly successful assignments under Coffee Corps, a program managed by the Coffee Quality Institute - the ACE project helped union and cooperative managers improve washing operations and technology. The project has trained farmers on post-harvest handling, upgraded the skills of washing station managers and trained cooperatives in contract and delivery agreements and requirements, and is currently facilitating the introduction of new washing technology that uses only a small fraction of the water required in the present systems.

\section{Emphasis on Inter firm Cooperation}

The main focus of the ACE coffee component is on strengthening the cooperation among smallholder producers through the development of coffee cooperatives and unions. The coffee unions were established to buy, consolidate and internationally market coffee supplied by smallholders through their cooperatives. The cooperatives buy, wash and consolidate members' coffee. Since the unions are owned by the cooperatives, these two sets of institutions form an efficient, vertically integrated operation. As a result, profits are returned to the small-scale farmers: in 2004 , the coffee unions paid out $\$ 1.63$ million in dividends to cooperative members, and the trend is strongly upward.

Linkages between cooperatives have resulted in improved coffee quality and operational efficiency. Cooperatives collaborate in contracting for transportation and warehousing services and share market information. They learn from each other and jointly access technical assistance in such areas as cupping, fermentation, water conservation and other processing activities. Important horizontal linkages also exist at the union level. In addition to sharing market information and contacts, solutions to shipping and logistical problems have often come through the assistance of other coffee unions. Sidama Union helped both Yirgacheffe and Kafa in their start-up periods to export containers of their coffee. All four unions have collaborated to make the internationally judged cooperative coffee competition and internet coffee auctions a success. Through such cooperation, the unions are making Ethiopian coffee more competitive in the world market, to the benefit of their members.

\subsection{Review of Empirical Studies}

Although there are a number of studies that have employed the value chain approach to agricultural commodities, there is no studies conducted to analyze the effectiveness of the value chain, except a single study conducted by M.Karthikeyan (2013). He used a value chain analysis to examine the effectiveness of Cooperatives in Coffee 
Value Chain in Sasiga woreda, East Wellega Zone, Oromia Region, Ethiopia. By using logit model he showed that trust between actors in the chain, accessibility to technology, timely distribution of market information, actors oriented training, delivery of products at right time and place and financial support to actors in the chain are factors affecting the effectiveness of coffee value chain. The study also indicated that there was strong linkage among chain actors. The study recommended that greater attention should be given by all stakeholders to further strengthen the linkage exchanging technologies and market information, offering sustained training, promoting self-financing strategies and by minimizing the adverse effect of practices which erodes members trust.

Birhanu, et al., (2013) also conducted study on Quality and Value Chain Analyses of Ethiopian Coffee. They argued in their study that Ethiopia is not benefited from coffee production because of two reasons: quality deteriorates along the value chain and the value addition is almost negligible. They reported that the profit flow back to Ethiopian poor farmers from the end users is less than $10 \%$. They recommended that actors in the value chain, government, and non-government organizations should divert their efforts toward reducing deteriorating quality in pre-harvesting and post-harvesting, and promote value addition.

Fitter and Kaplinsky (2001) used a value chain analysis to examine inter-country distributional outcomes of the global coffee sector by mapping input-output relations and identifying power asymmetries along the coffee value chain. Their study showed that returns to product differentiation taking place in the face of globalization do not accrue to the coffee producers. They also found that power in the coffee value chain was asymmetrical. At the importing end of the chain, importers, roasters and retailers compete with each other for a share of value chain rents but combine to ensure that few of the rents return to the farmer or the producer country.

Ponte (2002) also used a value chain analysis to examine the impact of deregulation, new consumption patterns and evolving corporate strategies in the global coffee chain on the coffee exporting countries in the developing world. The study concluded that the coffee chain was increasingly becoming buyer-driven and the coffee farmers and the producing countries were facing a crisis relating to changes in the governance structure and the institutional framework of the coffee value chain.

Abraham (2013) conducted study on vegetables value chain in Habro and Kombolcha woredas of Oromia Region. The study was aimed at identifying vegetable value chain and examining the performance of actors in the chain; analyzing the determinants of vegetable supply to the market in the study area; and identifying marketing channels and factors affecting outlet choice decisions of farm households. The result of the analysis revealed that the major actors in the woredas are input suppliers, vegetable producers, collectors, wholesalers, retailers, exporters and consumers. The study result also showed that vegetable producers are faced with lack of modern input supply and high postharvest losses. On marketing side, limited access to market, low price of product, lack of storage, lack of transport, low quality of product and lack of policy framework to control the illegal EthioSomalia trade route are the major problems. It was also found out that vegetable passes through several intermediaries with little value being added before reaching the end users. The chain is governed by wholesalers and exporters who have capital advantage over the other chain actors. Therefore, farmers are forced to capture a lower share of profit margin. The results of multinomial logit model also indicated that the probability to choose the collector outlet was significantly affected by access to extension service, owning transport facility, membership to any cooperatives and post-harvest value addition compared to wholesale outlet. Therefore, policy aiming at increasing farmers' access to modern inputs, developing and improving infrastructure, gender consideration, cooperative development and improving extension system are recommended to accelerate the chain's development.

Another value chain study conducted on off-season vegetables by USAID (2011) in Nepal indicated that the subsector faces some challenges such as unavailability of quality planting materials, lack of knowledge among the producers of the proper usage of fertilizers and pesticides as well as poor soil fertility management, lack of irrigation facilities, labor shortage, postharvest loss due the perishable nature of vegetables, limited access to reliable market information, unorganized market center, limited collection centers, and lack of proper packaging and transportation facilities. The study recommended short-term and long term infrastructural and institutional innovation to reduce the above challenges.

Dereje (2007) used value chain approach to study the competitiveness of Ethiopian coffee in the international market. The study indicates that Ethiopian farmers have low level of education, large family size with small farmland and get only $3 \%$ of the retail price in the German market. Thus, policy intervention was suggested to improve farmers' performance.

Horticulture value chain study conducted in Eastern parts of Ethiopia identified different problems on the chain (Bezabih, 2008). The major constraints of marketing identified by the study include lack of markets to absorb the production, low price for the products, large number of middlemen in the marketing system, lack of marketing institutions safeguarding farmers' interest and rights over their marketable produces (e.g. cooperatives), lack of coordination among producers to increase their bargaining power, poor product handling and packaging, imperfect pricing system and lack of transparency in market information communications.

The same result was found by study conducted on mango value chain by Dendena et al, (2009). The result of the study indicated that the subsector faces challenges such as; highly disorganized and fragmented industry with 
weak value chain linkages, long and inefficient supply chains, inadequate information flows and lack of appropriate production are explained as the major problems. The study recommended institutional innovation to reduce the above challenges.

\subsection{Conceptual Framework of the Study}

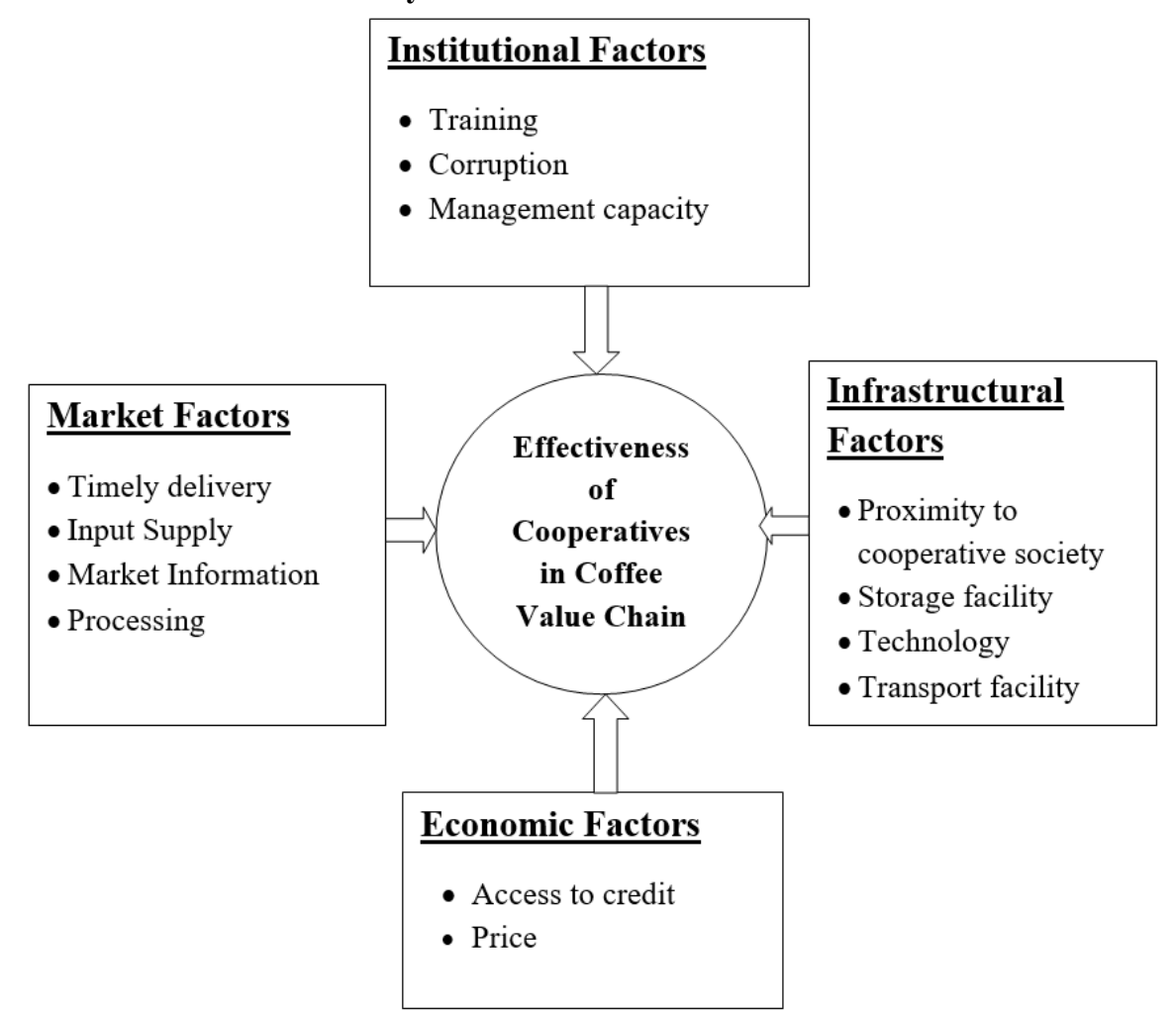

Figure 4: Conceptual Frame Work

Source: Own Computation, 2018

These are the determining factors affecting the effectiveness of coffee cooperatives in coffee value chain. The one direction of the lines show that the effectiveness of cooperatives in coffee value chain is affected by these four main factors; namely economic factors, institutional factors, infrastructural factors and market factors. This was discussed in detail under next session.

\section{PART THREE}

\section{RESEARCH METHODOLOGY}

\subsection{Description of the study area}

\subsubsection{Description of the Melka-ballo Woreda.}

The study was conducted in Melka ballo District, East Hararghe Zone, Oromia Regional State, eastern part of Ethiopia. Jaja is the administrative capital of the District and it is located $163 \mathrm{~km}$ west to Harar, the administrative capital of East Hararghe Zone and about $488 \mathrm{~km}$ east to Addis Ababa. The total area of the District is 1391.75. The woreda is bordered with Deder and Tullo woredas in the north, Kuni and Gola Oda woredas in the south, and Badanno and Mesela woredas in the east and west parts consecutively. According to the population forecast of 2012 by central statistical agency (CSA) the total population of the woreda is 204,636 of which female 100,095 and male 104,541. The majority of populations in the woreda drive their livelihood on agriculture.

The administrative and location map of Zonal and Districts of Oromia region is presented below; 


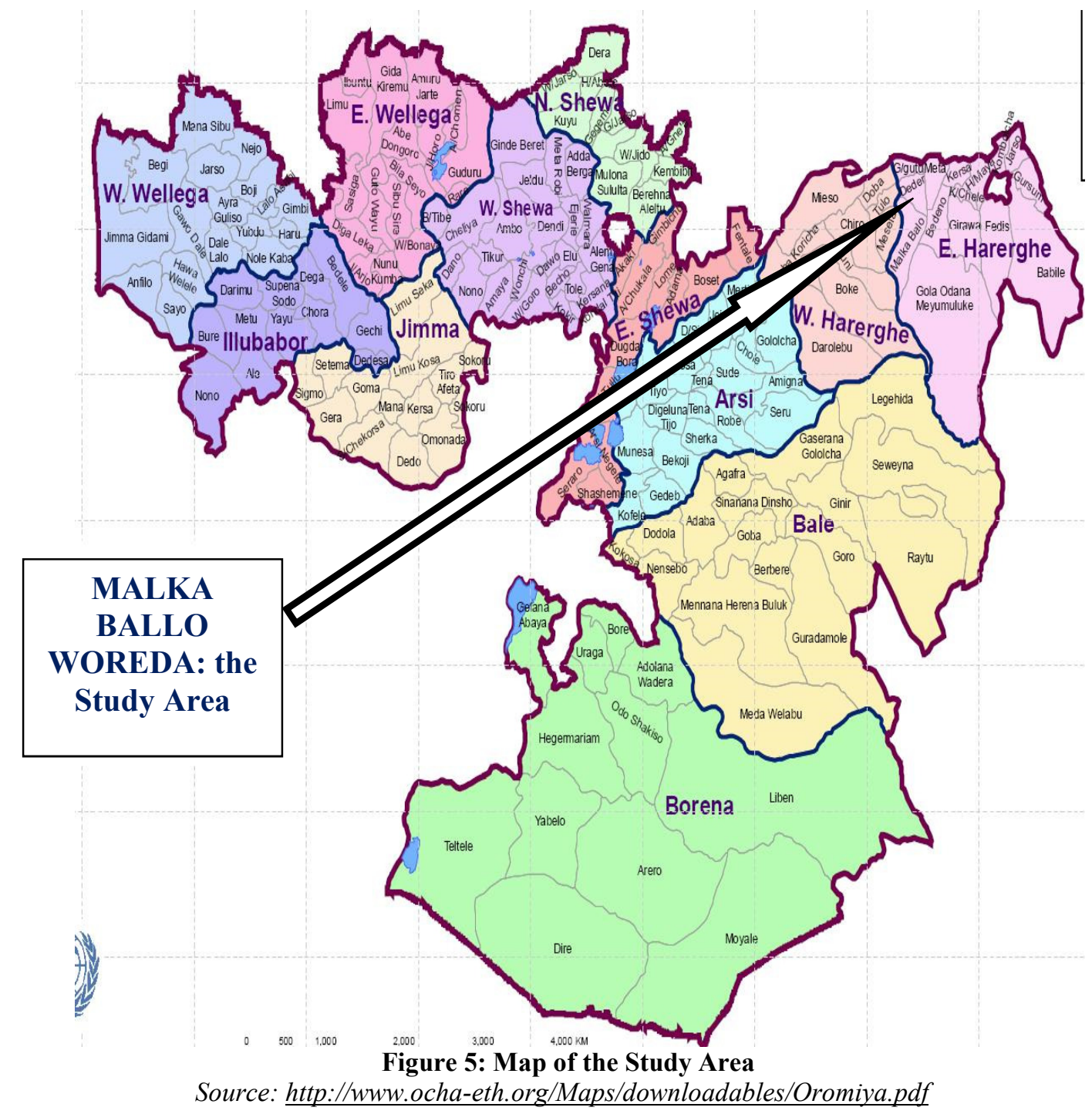

\subsection{Research design and Approach}

The type of research design employed under this study was descriptive. It was designed to describe actors in the coffee value chain and their roles and to describe the linkages between cooperatives and other actors in the coffee value chain. Moreover, in this study both quantitative and qualitative research approaches were employed.

\subsection{Target Population and Sample Frame}

In this study the target population was coffee producers who are members of coffee cooperative societies in Melkaballo woreda. In the study area, there are about 43 primary cooperative societies and one cooperative union. Table 2 below shows all cooperative societies operating in the district by their types. Among forty three cooperative societies, three of them are coffee producers' cooperatives and all of them were selected for the study purpose. 
Table 2: sample frame of the study

\begin{tabular}{|c|c|c|c|c|c|c|c|c|c|c|}
\hline \multirow[t]{2}{*}{$\frac{\pi}{Z}$} & \multirow{2}{*}{$\begin{array}{c}\text { Type of } \\
\text { Cooperative } \\
\text { Societies }\end{array}$} & \multirow{2}{*}{$\begin{array}{l}\text { Amount } \\
\text { in } \\
\text { number }\end{array}$} & \multicolumn{3}{|c|}{$\begin{array}{c}\text { Beginning } \\
\text { membership }\end{array}$} & \multicolumn{3}{|c|}{$\begin{array}{c}\text { Current } \\
\text { membership }\end{array}$} & \multirow[t]{2}{*}{$\begin{array}{l}\text { Beginning } \\
\text { capital }\end{array}$} & \multirow[t]{2}{*}{$\begin{array}{l}\text { Current } \\
\text { capital }\end{array}$} \\
\hline & & & $\mathrm{M}$ & $\mathrm{F}$ & $\mathrm{T}$ & $\mathrm{M}$ & $\mathrm{F}$ & $\mathrm{T}$ & & \\
\hline 1 & $\begin{array}{l}\text { Multipurpose } \\
\text { Cooperatives }\end{array}$ & 17 & 1207 & 138 & 1345 & 3393 & 878 & 4271 & $278,077.04$ & $9,960,201.54$ \\
\hline 2 & $\begin{array}{l}\text { Coffee } \\
\text { Cooperatives }\end{array}$ & 3 & 288 & 32 & 320 & 715 & 488 & 1203 & $80,876.15$ & $3,172,335.10$ \\
\hline 3 & $\begin{array}{l}\text { Consumer } \\
\text { Cooperatives }\end{array}$ & 1 & 32 & 32 & 64 & 32 & 32 & 64 & 15,000 & $31,000.90$ \\
\hline 4 & $\begin{array}{l}\text { Chat } \\
\text { Cooperatives }\end{array}$ & 2 & 194 & 10 & 204 & 254 & 36 & 290 & 22,780 & 55,200 \\
\hline 5 & $\begin{array}{l}\text { Honey } \\
\text { producers } \\
\text { Cooperatives }\end{array}$ & 1 & 32 & 2 & 34 & 32 & 2 & 34 & 9,860 & 10,800 \\
\hline 6 & $\begin{array}{l}\text { Fattening } \\
\text { Cooperatives }\end{array}$ & 1 & 33 & 4 & 37 & 33 & 4 & 37 & 7000 & 14,000 \\
\hline 7 & SACCOs & 15 & 980 & 581 & 1561 & 1444 & 819 & 2263 & 78,650 & 98,150 \\
\hline 8 & $\begin{array}{l}\text { Workers } \\
\text { Cooperatives }\end{array}$ & 2 & 67 & 13 & 80 & 67 & 13 & 80 & 34,800 & 43,000 \\
\hline 9 & $\begin{array}{l}\text { Handcraft } \\
\text { Cooperatives }\end{array}$ & 1 & 67 & 8 & 75 & 67 & 8 & 75 & 13,690 & 35,000 \\
\hline & Total & 43 & 2900 & 820 & 3720 & 6213 & 2280 & 8421 & $540,733.19$ & $13,419,687.54$ \\
\hline
\end{tabular}

Source: Melka-ballo woreda Cooperative Promotion Office, 2018

\subsection{Sampling Technique and Sample Size}

\subsubsection{Sampling Techniques}

In this study multi-stage sampling technique was applied. In the study area there are three coffee cooperative societies and all of them were taken for the study purpose. In the second stage, total number of member respondents was determined by using the statistical sample size determination table (table 3) and PPS (proportional to population size) method was used to get proportional member respondents from each cooperatives (table 4). Lastly, lottery method was employed to select individual respondents from each sampled cooperative societies.

\subsubsection{Sample Size Determination}

Total number of respondents was determined by using statistical sample size determination table (table 3 ). Accordingly, at a given population size of $\mathrm{N}=1203$, and at $95 \%$ confidence level, and margin of error $= \pm 5$ percent the total optimum sample size was 291.

$\mathrm{N}=$ Total population $=1203$

Confidence level $=95 \%$

Acceptable error (0.05)

$\mathrm{n}=$ sample size $=291$ 
Table 3: statistical sample size determination table

\begin{tabular}{|c|c|c|c|c|c|c|c|c|}
\hline \multirow[t]{2}{*}{ Population Size } & \multicolumn{4}{|c|}{$\begin{array}{r}\text { Confidence }=95 \% \\
\text { Margin of error }\end{array}$} & \multicolumn{4}{|c|}{$\begin{array}{c}\text { Confidence }=99 \% \\
\text { Margin of Error }\end{array}$} \\
\hline & $5.0 \%$ & $3.5 \%$ & $2.5 \%$ & $1.0 \%$ & $5.0 \%$ & $3.5 \%$ & $2.5 \%$ & $1.0 \%$ \\
\hline 10 & 10 & 10 & 10 & 10 & 10 & 10 & 10 & 10 \\
\hline 20 & 19 & 20 & 20 & 20 & 19 & 20 & 20 & 20 \\
\hline 30 & 28 & 29 & 29 & 30 & 29 & 29 & 30 & 30 \\
\hline 50 & 44 & 47 & 48 & 50 & 47 & 48 & 49 & 50 \\
\hline 75 & 63 & 69 & 72 & 74 & 67 & 71 & 73 & 75 \\
\hline 100 & 80 & 89 & 94 & 99 & 87 & 93 & 96 & 99 \\
\hline 150 & 108 & 126 & 137 & 148 & 122 & 135 & 142 & 149 \\
\hline 200 & 132 & 160 & 177 & 196 & 154 & 174 & 186 & 198 \\
\hline 250 & 152 & 190 & 215 & 244 & 182 & 211 & 229 & 246 \\
\hline 300 & 169 & 217 & 251 & 291 & 207 & 246 & 270 & 295 \\
\hline 400 & 146 & 265 & 318 & 384 & 250 & 309 & 348 & 391 \\
\hline 500 & 217 & 306 & 377 & 475 & 285 & 365 & 421 & 485 \\
\hline 600 & 234 & 340 & 432 & 565 & 315 & 416 & 490 & 579 \\
\hline 700 & 248 & 370 & 481 & 653 & 341 & 462 & 554 & 672 \\
\hline 800 & 260 & 396 & 526 & 739 & 363 & 503 & 615 & 763 \\
\hline 1,000 & 278 & 440 & 606 & 906 & 399 & 575 & 727 & 943 \\
\hline 1,200 & 291 & 474 & 674 & 1,067 & 427 & 636 & 827 & 1,119 \\
\hline 1,500 & 306 & 515 & 759 & 1,297 & 460 & 712 & 959 & 1,376 \\
\hline 2,000 & 322 & 563 & 869 & 1,655 & 498 & 808 & 1,141 & 1,785 \\
\hline 2,500 & 333 & 597 & 952 & 1,984 & 524 & 879 & 1,288 & 2,173 \\
\hline 3,500 & 346 & 641 & 1,068 & 2,565 & 558 & 977 & 1,510 & 2,890 \\
\hline 5,000 & 357 & 678 & 1,176 & 3,288 & 586 & 1,066 & 1,734 & 3,842 \\
\hline 7,500 & 365 & 710 & 1,275 & 4,211 & 610 & 1,147 & 1,960 & 5,165 \\
\hline 10,000 & 370 & 727 & 1,332 & 4,899 & 622 & 1,193 & 2,098 & 6,239 \\
\hline 25,000 & 378 & 760 & 1,448 & 6,939 & 646 & 1,285 & 2,399 & 9,972 \\
\hline 50,000 & 381 & 772 & 1,491 & 8,056 & 655 & 1,318 & 2,520 & 12,455 \\
\hline 75,000 & 382 & 776 & 1,506 & 8,514 & 658 & 1,330 & 2,563 & 13,583 \\
\hline 100,000 & 383 & 778 & 1,513 & 8,762 & 659 & 1,336 & 2,585 & 14,227 \\
\hline 250,000 & 384 & 782 & 1,527 & 9,248 & 662 & 1,347 & 2,626 & 15,555 \\
\hline 500,000 & 384 & 783 & 1,532 & 9,423 & 663 & 1,350 & 2,640 & 16,055 \\
\hline $1,000,000$ & 384 & 783 & 1,534 & 9,512 & 663 & 1,352 & 2,647 & 16,317 \\
\hline $2,500,000$ & 384 & 783 & 1,536 & 9,567 & 663 & 1,353 & 2,651 & 16,478 \\
\hline $10,000,000$ & 384 & 784 & 1,536 & 9,594 & 663 & 1,354 & 2,653 & 16,560 \\
\hline $100,000,000$ & 384 & 784 & 1,537 & 9,603 & 663 & 1,354 & 2,654 & 16,584 \\
\hline $300,000,000$ & 384 & 784 & 1,537 & 9,603 & 663 & 1,354 & 2,654 & 16,586 \\
\hline
\end{tabular}

Source: Gang (1999): Estimating sample size for a descriptive study in quantitative research.

Next, to get respondents from each selected cooperatives, PPS method was used. Accordingly, 237, 26 and 28 respondents were selected from Hundee-Lelisaa, Madda-Guddinaa and Rakkoo-Baas cooperative societies respectively (table 4). Finally, lottery method was used to select individual member respondents from each sampled cooperative society. 
Table 4: Sample Units of Respondents

\begin{tabular}{|l|l|l|l|l|l|l|}
\hline \multirow{2}{*}{ Coffee cooperatives } & \multicolumn{2}{l|}{ Total Population } & \multicolumn{3}{l|}{ Sample Proportion } \\
\cline { 2 - 7 } & $\mathrm{M}$ & $\mathrm{F}$ & $\mathrm{T}$ & $\mathrm{M}$ & $\mathrm{F}$ & $\mathrm{T}$ \\
\hline Hundee-Lelisaa & 526 & 456 & 982 & 127 & 110 & 237 \\
\hline Madda-Guddinaa & 96 & 11 & 107 & 23 & 3 & 26 \\
\hline Rakkoo-Baas & 93 & 21 & 114 & 23 & 5 & 28 \\
\hline Total & 715 & 488 & 1203 & 173 & 118 & 291 \\
\hline
\end{tabular}

Source: Melka-ballo woreda Cooperative Promotion Office, 2018

In addition, 34 actors in coffee value chain were selected and incorporated purposively due to having direct and indirect relationship with the activities of coffee value chain as shown in table5.

Table 5: List of respondents for KII and FGD

\begin{tabular}{|l|l|l|}
\hline S.No. & Respondents & No of respondents \\
\hline & & \\
\hline $\mathbf{1}$ & Management committee from each PCCs & $5^{*} 3=15$ \\
\hline $\mathbf{3}$ & Promoters & 3 \\
\hline $\mathbf{5}$ & Local consumers & 10 \\
\hline $\mathbf{6}$ & Private traders & 3 \\
\hline $\mathbf{7}$ & Oromia coffee union staffs & 2 \\
\hline & Private exporter & 1 \\
\hline
\end{tabular}

\subsection{Types and Sources of Data}

Primary and secondary data were used. Primary data was collected from members of the sampled coffee cooperative societies and secondary data was collected from records of different books of the societies, reports, journals, thesis, internet sources that are appropriate for the study.

\subsection{Method of Data Collection}

The primary data necessary for the study were collected from member respondents by using questionnaires. The open-end and closed - end questionnaire was pretested to identify and avoid vague and sensitive questions. To make the communication easier during collection of data from the respondent, the questionnaire was prepared in English and translated to Afan Oromo for final administration.

To collect primary data five enumerators working as development agent (DA) were recruited and trained on how to conduct and approaches sampled members. The researcher preferred DAs because they have enough knowledge and experience in cooperatives and they have intimate relationship with sampled cooperatives and their members since they are working with cooperatives and members. The researcher closely supervised them during data collection period.

For the sake of triangulating the data collected from member respondents, qualitative data was collected from management committee of sampled cooperatives by conducting focus group discussion (FGD). Three FGDs were conducted with 15 management committees, 5 from each of sampled cooperatives through checklist. Besides, key informant interviews (KIIs) were also employed among 3 Melka-ballo wored's Cooperative Promoters, 10 local consumers, 2 Oromia farmers' coffee union staffs, 3 Private traders and 1 Private exporter.

\subsection{Method of Data Analysis}

Prior of analyzing the collected data, checking its completeness, editing, organizing and coding activities was carried out to attain the stated objectives of the study. In this study, to address the specific objectives of the study two methods of data analysis were used, namely descriptive statistics and econometric model analysis.

\subsubsection{Descriptive Analysis}

The first and second objectives were analyzed by descriptive statistics such as percentage and frequency. The third objective was analyzed using three level likert scales representing (1) - strong, (2) - medium and (3) - weak.

\subsubsection{Econometric Model}

Binary Logistic regression was used to analyze determining factors affecting the effectiveness of coffee cooperatives in coffee value chain, which is the fourth objective to be addressed in this study. Chi-square test was used to test the significance of the binary logistic regression results.

\subsubsection{Specification of Econometric Model}

When any of the explanatory variables in a regression model are binary, one can represent them as dummy variables and proceed with the analysis using linear regression. However, the application of the linear regression model when the independent variable is binary is more complex (Pindyck and Rubinfeld, 1981). Binary logistic regression model assumes that individuals are faced with the choice between two alternatives and their choice 
depends on the characteristics. Thus, the purpose of qualitative choice model is to determine the probability that an individual with a given set of alternatives will make one choice rather than the alternative. A number of statistical model have been developed that allow studying qualitative variables; the two that have been most popular are the "logistic regression" and the "probit model". These models can easily be applied to cases where the dependent variable is either nominal or ordinal, and has two or more levels, and the independent variables are any mix of qualitative and quantitative predictors. Both are estimated by maximum likelihood, consequently, goodness of fit and inferential statistics are based on the log likelihood, chi-square test.

\subsubsection{Binary Logistic Regression Model}

Logistic regression is a useful way of describing the relationship between one or more independent variables and a binary response variable, expressed as a probability that has only two values. The dependent variable is dummy (binary) variable (Hosmer and Lemeshow, 1989), which takes the value zero or one depending on whether or not coffee cooperatives are engaged in value addition. However, the explanatory variables are either continuous or dummy. The logistic and probit model are comparable; the main difference being the logistic function has slight flatter tails that is, the normal curve under logit function approaches the axes more quickly than in the case of probit function. Ignoring minor differences Laio, (1994), Gujarati, (1988), Pindyck and Rubinfeld, (1981), pointed out the probit and logistic model are quite similar. They usually generate predicted probabilities that are almost identical, though the logistic model is preferred over the probit and it is simpler in estimation than the probit model. Therefore, binary logistic regression model was preferred to study the Effectiveness of Cooperatives in Coffee Value Chain (ECCVC).

Binary logistic regression was employed to analyze variables that influence the effectiveness of cooperatives in coffee value chain. The dependent variable in this study "the effectiveness of cooperatives in coffee value chain" was a dummy (binary) variable which takes a value Zero or one depending on whether cooperatives are engaged in value addition. It was analyzed by the following model: (Gujarit, 1988);

$$
\mathrm{Pi}=\mathrm{F}(\mathrm{Zi})
$$

Where, $\mathrm{Pi}=$ the likelihood of the effectiveness of cooperatives in coffee value chain.

The binary variable, $\mathrm{Pi}=1$, if cooperatives are effective in coffee value chain and $\mathrm{Pi}=0$, if otherwise.

$\mathrm{Zi}=$ Estimated independent variable for the $\mathrm{i}^{\text {th }}$ observation,

$\mathrm{F}=$ the functional relationship between $\mathrm{Pi}$ and $\mathrm{Zi} . \mathrm{i}=1,2 \ldots \mathrm{m}$ are observation on variables for cooperatives in coffee value chain, $\mathrm{n}$ being the sample size 291 .

$\mathrm{Xji}=$ the $\mathrm{j}^{\text {th }}$ explanatory variable for the $\mathrm{i}^{\text {th }}$ observation $=1,2 \ldots \ldots \ldots \ldots .$.

$\mathrm{Bj}=\mathrm{a}$ parameter,

$\mathrm{j}=0,1$

$\mathrm{n}$. where $\mathrm{n}$ is the total number of explanatory variables.

The logit model assumes the underlying index; $\mathrm{Zi}$ is a random variable that predicts the probability of effectiveness of cooperatives in coffee value chain.

$P i$

$$
\begin{gathered}
=\frac{1}{1+e^{-Z i}}-\frac{1}{1+e^{Z i}} \\
1-P i=\frac{P}{1}=\frac{1}{1+p^{2}}
\end{gathered}
$$

If $\mathrm{Pi}$ is the probability of effectiveness of cooperatives in coffee value chain, then (1-Pi) is otherwise.

If the disturbance term Ui is taken into account, the logit model becomes

$$
Z i=\mathrm{Bo}+\sum_{i=1}^{m} \mathrm{BiXi}
$$

$$
+\mathrm{Ui}
$$

\subsubsection{Multicollinearity Test}

Before conducting of the regression analysis, multicolliniarity problem of explanatory variables was tested. There are two measures that are often suggested to test the problems of the existence of multicollinearity. These are variance inflation factor (VIF) for association among the continuous explanatory variables and contingency coefficient (CC) for dummy variables.

Variance inflation factor (VIF) is used to check multicollinearity of continuous variables. As $\mathrm{R}^{2}$ increases towards 1 , it is a co linearity of explanatory variables. The larger the value of VIF, the more the troublesome or collinear is the variable $\mathrm{Xi}$. As a rule of thumb if the VIF greater than 10 (this will happen if $\mathrm{R}^{2}$ is greater than 0.8 ) the variable is said to be highly collinear (Gujaraiti, 2003). 


$$
\mathrm{VIF}(\mathrm{Xi})=\frac{1}{1-R^{2}}
$$

$\mathrm{R}^{2}$ is the coefficient of determination when the variable $\mathrm{Xj}$ is regarded on the other explanatory variable. VIF value greater than 10 is used as a signal for a strong multicollinearity (Gujarati, 1995).

Contingency coefficient (CC) was used to check multicollinearity of discrete variables. It measures the relationship between the row and column variables across tabulation. The range between $0-1$, with " 0 " indicating no association between the row and column variables and value close to " 1 " indicating high degree of association between variables. The decision criterion $(\mathrm{CC}<0.75)$ is that variables with the contingency coefficient $(\mathrm{CC})$ is computed as follows.

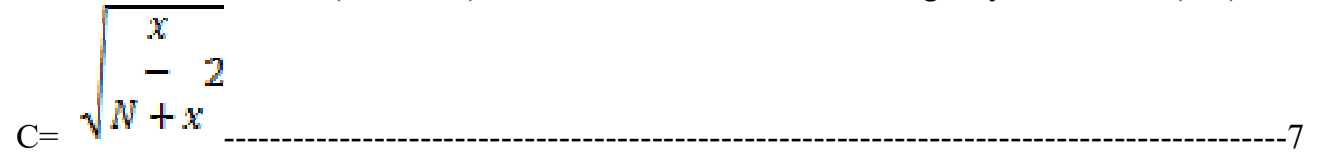

As cited in Gujarait, (1995), if the value of $\mathrm{C}$ is greater than 0.75 , the variables are said to be collinear.

In general, the Statistical software called the statistical package for social science (SPSS) version 20.0 was used to compute CC and to analyze the collected data at $95 \%$ confidence level.

\section{Operational Definition and Assumptions of the Variables \\ Dependent Variable:}

Effectiveness of Coffee Cooperatives in Coffee Value Chain (ECCVC):- Cooperatives that are engaged on value adding activities are more likely effective in the value chain. Hence, cooperatives that engaged in value addition assume 1 , and 0 if otherwise.

\section{Explanatory Variables:}

Economic Factors

Access to Credit: Lack of credit limits the purchasing capacity of cooperatives and members in the chain to purchase inputs and undertake activities related to production which in turn have a likely effect on the effectiveness of cooperatives in coffee value chain. This variable is a dummy variable which takes 1 if members and cooperatives have got access to credit, and 0 if otherwise. Access to credit was hypothesized to have a positive effect on the effectiveness of cooperatives in coffee value chain.

Pricing: In Ethiopia, the number of coffee farmers is increasing from time to time but due to the relatively low price of coffee paid to farmers, many coffee producers are shifted to high value cash crops such as chat for comparative advantage (Tirufat, 2011). Members are motivated to produce and supply more coffee to market if the prices offered are attractive. The better the prices offered by cooperatives the more likely the effectiveness of cooperatives in the coffee value chain. Cooperatives are assumed to pay better prices for members' coffee produce as compared to other actors. This variable is a dummy variable that assumes 1 if cooperatives offer better prices than other actors, and 0 if otherwise. Pricing was hypothesized to have a positive effect on the effectiveness of cooperatives in coffee value chain.

\section{Infrastructural Factors}

Proximity to cooperative: refers to the distance of cooperative center from the house of the individual member. It determines members ' decision to participate or not in cooperatives. It is measured in terms of hours. It is a dummy variable taking value 1 if the distance is short as much as possible and 0 otherwise. This variable was expected or hypothesized to influence effectiveness of cooperatives in the value chain negatively.

Storage facility: Coffee handling is one of the crucial processes influencing quality, and thus needs due care. The dried coffee should not be stored in an environment where it can pick up or lose moisture and undesirable smell. Dry coffee should not be stored in sisal bags and it should be placed on wooden pallets raised $15-20 \mathrm{~cm}$ above the ground level and about $30 \mathrm{~cm}$ away from the wall or roof to encourage ventilation, as well as about $1 \mathrm{~m}$ away from corrugated iron sheet roof (Achoth, 2005). This variable was assumed to have positive effect on the effectiveness of cooperatives in coffee value chain. Quality of coffee that if it is not up to standard may reduce the effectiveness of cooperatives in coffee value chain. It is a dummy variable, which takes the value 1 if cooperatives have standard storage facility, and 0 if otherwise.

Technology: Technology includes the use of materials, tools, new techniques of production, and sources of power to make life easier or more pleasant and work more productive. The use of technology increases the coffee production efficiency and thereby affects the effectiveness of cooperatives in coffee value chain. Technology is a dummy variable which assumes the value 1 if members use up-to-date technology like quality testing technology, standardized bean balance...etc, and 0 if otherwise. Technology was hypothesized to have a positive effect on the effectiveness of cooperatives in coffee value chain.

Transport facility: Transportation is an important activity in coffee value chain, which is a means of distribution of products to the places of demand (Schipmann, 2006) and this variable is assumed to have a positive effect on the effectiveness of cooperatives in coffee value chain. Availability of transportation facility is an important 
variable, which enhances the efficiency of means of transportation and distribution of products from producers to market and between different actors. This variable is a dummy variable, which takes 1 if there is sufficient transport facility and 0 if otherwise.

\section{Institutional Factors}

Corruption: It is a practice of getting a benefit without legal procedure. Corruption diminishes the viability of the cooperatives by reducing the productivity and the effectiveness of cooperatives in coffee value chain. This variable is a dummy variable which assumes 1 if there is no corruption, and 0 if otherwise. This variable was hypothesized to have negative effect on ECCVC.

Management Capacity: Many cooperatives employ managers who are not well qualified, leading to general mismanagement and inefficiencies. Good management capacity is assumed to improve the business performance of cooperatives that in turn enhances the effectiveness of cooperatives in coffee value chain. This variable is a dummy variable which takes 1 if management is qualified and has the required managerial capacity - to have planning, organizing, coordinating, directing, controlling, and otherwise 0 . In addition, this variable was expected to have positive influence on ECCVC.

Training: Building capacities of coffee producers, processors, traders and exporters through training on coffee processing and quality management system should be done so that they can upgrade their knowledge, skill and attitude on processing and method of production. No wonder that the trainings provided to cooperatives will improve the effectiveness of cooperatives in coffee value chain. This variable is a dummy variable which assumes 1 if cooperative members, employees and boards have got sufficient training, and 0 if otherwise. This variable was hypothesized to have positive influence on ECCVC.

\section{Market Factors}

Input Supply: This being the first step in the production process considers everything from the seeds to the technical equipment needed for the production of the concerned product. Input supply facilitates the primary production of raw materials (Schipmman, 2006). The most important input for coffee growers are improved coffee seedlings, drying beds, sprayer,....etc. This variable is a dummy explanatory variable, which assumes 1 if there is sufficient input supply and 0 otherwise. Sufficient supply of input was hypothesized to have a positive effect on the effectiveness of cooperatives in coffee value chain.

Market Information: Market information is vital to make decisions related to new market opportunities, changing needs of the consumer and how market trends influence buying (CIAT, 2004). Cooperatives as a business enterprise require dynamic market information to make business decisions and to gain competitive advantage in the chain. Access to timely market information has positive effect on the effectiveness of cooperatives in coffee value chain. This variable is a dummy variable that assumes 1 if cooperatives have access to timely market information, and 0 if otherwise

Processing: It is assumed that processing is the major activity in coffee value chain which has a bearing on the effectiveness of cooperatives in the coffee value chain and affecting ECCVC positively. The variable is a dummy variable which assumes 1 if cooperative members use sun dried processing (dry method of processing) and 0 if dried mechanically (wet method).

Timeliness in delivery: It is speed and time of product/service delivery. It is a dummy variable taking value 1 if the required product/service is delivered on time and 0 otherwise. This variable was assumed to influence effectiveness of cooperatives in coffee value chain positively.

\section{CHAPTER FOUR \\ DATA PRESENTATION, ANALYSIS AND INTERPRETATION}

This chapter deals with the data analysis and interpretation of the survey results, FGDs and KIIs. The descriptive analysis was done to describe the demographic characteristics of the respondents, to describe the role of actors and to examine the level of their relationships in the CVC. Econometric analysis (Binary Logistic regression) was used to analyze factors that influence the effectiveness of cooperatives in coffee value chain. Chi-square test was used to test the significance of binary logistic regression results. Contingency coefficient (CC) was also calculated to test the multicollinearity problem between explanatory variables.

\section{Results of Statistical Descriptive Analysis}

\subsection{Demographic Profile of Member Respondents}

The demographic characteristics of respondents such as age, gender, educational level, marital status and family size are presented as follow. In this study respondents refer to the selected members of the primary coffee cooperatives (PCCs). 
Age of Respondents

Table 6: Distribution of respondents by age

\begin{tabular}{|l|l|l|l|}
\hline Demographic Characteristics & Category & Frequency & Percent \\
\hline \multirow{4}{*}{ Age } & Young(14-35) & 163 & 56 \\
\cline { 2 - 4 } & Middle(36-50) & 113 & 39 \\
\cline { 2 - 4 } & Old (>50) & 15 & 5 \\
\cline { 2 - 4 } & Total & $\mathbf{2 9 1}$ & $\mathbf{1 0 0}$ \\
\hline
\end{tabular}

Source: Computed from survey, 2018

For the purpose of this study age of respondents was categorized into three categories as young, middle and old age. This category is based on the illegibility of cooperatives membership. Young age ranges from 14 up to 35 years, middle age ranges from 36 up to 50 years and old includes those above 50 years. Table 6 , shows that majority of the respondents $163(56 \%)$ were young followed by $113(39 \%)$ middle age and $15(5 \%)$ old age respectively. This implies that the coffee cooperatives membership was built on young age group who are energetic work force. This may help the cooperative societies in building effective value chain.

Gender of respondents

Table 7: Distribution of respondents by sex

\begin{tabular}{|l|l|l|l|}
\hline Demographic Characteristics & Category & Frequency & Percent \\
\hline \multirow{3}{*}{ Gender } & Male & 173 & 59.5 \\
\cline { 2 - 4 } & Female & 118 & 40.5 \\
\cline { 2 - 4 } & Total & $\mathbf{2 9 1}$ & $\mathbf{1 0 0}$ \\
\hline
\end{tabular}

Source: Computed from survey, 2018

It was found that majority of the respondents 173(59.5\%) were male, while $118(40.5 \%)$ were female (See Table 7). This shows that, majority of members of PCCs were male which shows domination of men members which needs women encouragement.

Educational Level of Respondents

Table 8: Distribution of respondents by educational level

\begin{tabular}{|l|l|l|l|}
\hline Demographic Characteristics & Category & Frequency & Percent \\
\hline Educational Level & Illiterate & 114 & 39 \\
\cline { 2 - 4 } & Read and Write & 67 & 23 \\
\cline { 2 - 4 } & Primary(1-6) & 93 & 32 \\
\cline { 2 - 4 } & Secondary(7-12) & 17 & 6 \\
\cline { 2 - 4 } & Total & $\mathbf{2 9 1}$ & $\mathbf{1 0 0}$ \\
\hline
\end{tabular}

Source: Computed from survey, 2018

It was found that in table 8 above, 114(39\%) were illiterate, followed by 67 (23\%) who can read and write, 93(32\%) primary and $17(6 \%)$ secondary respectively. Education is very important for members to know their rights, responsibilities and also benefits of cooperatives. There for, the survey result shows that majority of respondents $177(61 \%)$ were literate or minimum can read and write which is good opportunity of coffee cooperatives in building effective coffee chain.

Marital Status of Respondents

Table 9: Distribution of respondents by marital status

\begin{tabular}{|l|l|l|l|}
\hline Demographic Characteristics & Category & Frequency & Percent \\
\hline Marital Status & Single & 0 & 0 \\
\cline { 2 - 4 } & Married & 279 & 96 \\
\cline { 2 - 4 } & Divorced & 3 & 1 \\
\cline { 2 - 4 } & Widowed & 9 & 3 \\
\cline { 2 - 4 } & Total & $\mathbf{2 9 1}$ & $\mathbf{1 0 0}$ \\
\hline
\end{tabular}

Source: Computed from survey, 2018

Marital status refers to the relationship of member respondents expressed in terms of marriage. Result of survey revealed that almost all of the respondents 279 (96\%) were married, followed by 9 (3\%) widowed, and 3(1\%) divorced respectively (See Table 9).

Family Size of the Respondents

Table 10: Distribution of respondents by family size

\begin{tabular}{|l|l|l|l|}
\hline Demographic Characteristics & Category & Frequency & Percent \\
\hline Family Size & Small(1-4) & 131 & 45 \\
\cline { 2 - 4 } & Medium(5-8) & 137 & 47 \\
\cline { 2 - 4 } & Big(Above 8) & 23 & 8 \\
\cline { 2 - 4 } & Total & $\mathbf{2 9 1}$ & $\mathbf{1 0 0}$ \\
\hline
\end{tabular}

Source: Computed from survey, 2018 
Family size refers to the number of family of members including household which is expressed by numbers. Table 10 reveals that majority of the respondents 137 (47\%) were with medium family size, followed by 131 (45\%) and $23(8 \%)$ small and big size family, respectively. It was found that the family size of almost all of member respondents were small and medium size.

\subsection{Actors and their Roles in Coffee Value Chain}

4.2.1. Mapping of overall coffee value chain actors exist in Melka-ballo coffee cooperatives;

According to McCormick and Schmitz (2002) cited in Abraham, (2013), value chain mapping enables to visualize the flow of the product from conception to end consumers through various actors. It also helps to identify the different actors involved in the value chain, and to understand their roles and linkages.

To sketch the value chain map, discussions were made with different actors engaged in the chain and members of primary coffee cooperatives in the study area. Consequently, the current coffee value chain map in Melka-ballo woreda is depicted in Figure 6. The main actors currently involving in coffee value chain in Melka-ballo woreda are; woreda cooperative promotion office, woreda Agriculture and Rural Development Office, Coffee seedling nurseries, coffee producers (members of the coffee cooperatives), primary coffee cooperatives, private intermediaries (retailers and wholesalers), cooperative unions, Oromia Cooperative Bank, Coffee Standard and Quality Inspection Center, Ethiopian commodity exchange, exporters, contrabandists and local users.

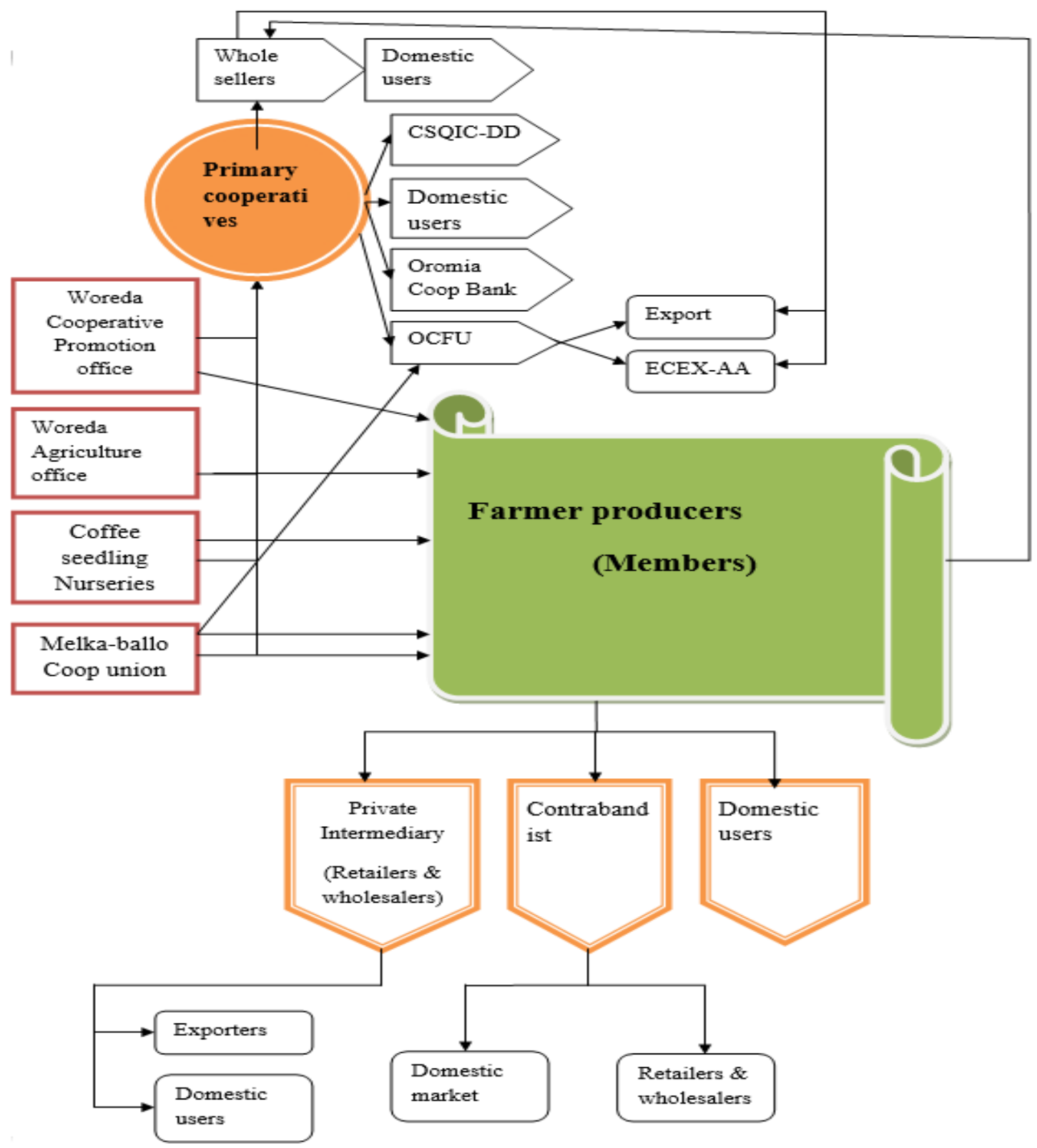

Figure 6: mapping of overall CVC actors in the study area

The value chain map highlighted the involvement of diverse actors who are participated directly (primary 
actors) or indirectly (supportive actors) in the value chain and their roles. According to KIT et al. (2006), cited in Abraham 2013, the primary actors are those involved in commercial activities in the chain (input suppliers, producers, traders, consumers) and supportive actors are those that provide financial or non-financial support services, such as credit agencies, technical service providers, government, NGOs, cooperatives, researchers and extension agents.

\section{Primary actors and their roles in Melka-ballo coffee value chain}

The primary actors in coffee value chain in Melka-ballo woreda were coffee seedling nurseries, coffee producers, primary cooperatives, cooperative unions, private intermediaries (retailers and wholesalers), exporters, contrabandists and local users. Each of these actors adds value in the process of changing product title. Some roles/functions are performed by more than one actor, and some actors perform more than one role.

\section{Input Suppliers}

There are many actors whose role is to supply farm inputs to coffee producers in the study area. Coffee seedling nurseries, primary cooperatives and cooperative union are the main source of input suppliers. All such actors are responsible to supply agricultural inputs like improved coffee seedlings, coffee drying beds and farm implements which are essential inputs at the production stage. Regarding fertilizers, all farmers used only organic fertilizer (manure and compost) because of organic coffee production. The result of the study indicated that out of the total respondents only $90(31 \%)$ of the respondents use coffee drying beds. The main reason indicated for not using coffee drying beds was unavailability of coffee drying beds at required amount.

\section{Producers}

Coffee growers are the major actors and a base of the value chain functions right from farm preparation to post harvest handling and marketing. The major value chain functions that coffee growers perform include ploughing, planting, irrigating, weeding, pest/disease controlling, collecting, drying and storing safely.

The quality standards of Ethiopian coffee are classified according to their origin of production. The diverse agro-climatic conditions make growing coffee highly cost-effective and competitive in the study area. Among the best-known coffee varieties in Ethiopia are Harar, Wellega, Limu, Sidama and Yirgacheffee take the priority. The first type, Harar is the highest premium coffee in Ethiopia as well in the world. Harar coffee has medium size bean, with a greenish-yellowish color with medium level of acidity and a distinctive mocha flavor (ECEX, 2008). Unfortunately, these opportunities have not been exploited by the farmers due to lower irrigation facility and lower control of contrabandists who bring low quality coffee from other parts of the country to mix with Harar coffee then supply to the market. This resulted in low amount of coffee production and low quality coffee supply to the market which brought fall down of coffee price in the market. Coffee production in the study area was based on rain fed and irrigation system. Out of the total respondents only $84(29 \%)$ of the respondents argued that they got irrigation facility.

Post-harvest handling, which includes different activities like drying, sorting, grading, packing and storing are done by the farmers themselves at home. Survey result also indicated that $96(33 \%)$ of sample producers conduct sorting, cleaning and grading of coffee by separating premature from matured coffee seedlings. Because, during collection of coffee seedlings, it was found out that farmers mix some premature seedlings with matured seedling and dry together. The main reason for this is that they presumed that premature seedlings are relatively few and never affect the quality of the whole coffee. So, they lack of awareness about coffee quality.

\section{Private intermediaries}

Private intermediaries are retailers and wholesalers. Retailers are licensed small and medium local coffee traders who purchase coffee from producers and contrabandists. Retailers' involvement in the chain includes buying of coffee, drying, grading and selling to either consumers in small amounts or wholesalers at large quantity. Sometime, they sale it to primary coffee cooperatives and cooperative unions. Retailers are key actors in coffee value chain because, they are the last link between producers and consumers.

On the other hand, wholesalers are big private traders who purchase coffee from producers (through their agents), and private collectors such as retailers and contrabandists in larger volume than any other actors. Wholesalers are mainly involved in buying and processing coffee and bring to auction center and supplying them to exporters. Through processing, wholesalers add value to the coffee. They have better storage, transport and communication access than other traders. They are located in Dire Dawa, but they operate on different woredas through their agents on woredas.

\section{Contrabandists}

Contrabandists are unlicensed coffee traders who purchase coffee from individual farmers by moving from one area to another, because, they are illegal traders. Their essential role is bringing coffee from very remote areas to the market and they transfer the coffee either to the retailers or to wholesalers immediately. Sometimes they move from door to door to collect the coffee from remote areas.

\section{Exporters}

Coffee exporters are companies who, upon being licensed to trade coffee by the appropriate government organ and fulfilling the requirements set by the ministry, and upon purchasing coffee from the ECEX prepares, processes 
and exports coffee in compliance with the export quality and standards. Exporters are clearly the most powerful of the private intermediaries as they hold contacts with international buyers. They are centralized in Addis Ababa and Dire Dawa and own processing plants where coffee is transformed into export quality beans.

\section{Local users}

Consumers are those who purchase the product for consumption. About two types of coffee consumers were identified: households, and cafes and restaurants. The households are urban and rural dwellers who purchase and consume coffee. Households purchase coffee directly from retailers. Farmers also make important segment of the rural consumers since they consume part of their produces. The survey result indicated that, approximately on average, $12 \%$ of coffees produced in 2017 were consumed by the producers.

Supporting actors and their roles in Melka-ballo coffee value chain

Supporting actors are those who provide supportive services including training and extension, information, financial and research services. According to Martin et al. (2007), access to information or knowledge, technology and finance determines the state of success of value chain actors. Woreda cooperative promotion office, woreda Agriculture and Rural Development Office, Primary coffee cooperatives, cooperative unions, Oromia Cooperative Bank (OCB), Coffee Standard and Quality Inspection Center (CSQIC), ECEX and NGOs are main supporting actors who play a central role in the provision of such services in Melka-ballo coffee value chin.

\section{Training and Extension Services}

Woreda cooperative promotion office, cooperative unions, Ethiopian commodity exchange and NGOs are the main actors providing training to farmers. The survey result revealed that $46 \%$, of member producers were participated in training that were organized in the last three years (table 11). The result also shows that most of the trainings were given on coffee quality. Training on cooperative legal system and Cash management and accounting were also given for committee members and managers of the coffee cooperatives.

Regarding extension service, woreda Agriculture and Rural Development Office, through its DAs is the major actor who provides extension and advisory service on coffee production and management practices. Among the total sample farmers $34.0 \%$ got extension and advisory services on the coffee value chain in last year (table 11).

\section{Information and Financial services}

Woreda cooperative promotion office, woreda Agriculture and Rural Development Office, Primary coffee cooperatives and cooperative unions are the main actors feeding information to coffee producers. Out of the sample farmers $148(51 \%)$ indicated that they are getting information particularly of input availability and price from primary cooperatives and DAs (table 11). But they also argued that they rarely receive market information related to coffee price or they receive outdated market information.

In the study area, with regard to financial service primary cooperatives, cooperative unions, Oromia Cooperative Bank and individual lenders have been identified as a potential source for coffee producers, coffee cooperatives and Melka-ballo cooperative union. The survey result also showed that only $63(21.5 \%)$ of sample respondents took credit (table 11). Most of the respondents' reasons for not participating in credit market were religious law which forbids either taking or giving interest.

Table 11: Supporting service provided to members and board of the PCCs

\begin{tabular}{|l|l|l|l|}
\hline Type of supporting Services & Response & Frequency & Percent \\
\hline Training service & Yes & 134 & 46.0 \\
\cline { 2 - 4 } & No & 157 & 54.0 \\
\cline { 2 - 4 } & Total & $\mathbf{2 9 1}$ & $\mathbf{1 0 0 . 0}$ \\
\hline \multirow{5}{*}{ Extension service } & Yes & 99 & 34.0 \\
\cline { 2 - 4 } & No & 192 & 66.0 \\
\cline { 2 - 4 } & Total & $\mathbf{2 9 1}$ & $\mathbf{1 0 0 . 0}$ \\
\hline Market information & Yes & 148 & 51.0 \\
\cline { 2 - 4 } & No & 143 & 49.0 \\
\cline { 2 - 4 } & Total & $\mathbf{2 9 1}$ & $\mathbf{1 0 0 . 0}$ \\
\hline Credit services & Yes & 63 & 21.5 \\
\cline { 2 - 4 } & No & 228 & 78.5 \\
\cline { 2 - 4 } & Total & $\mathbf{2 9 1}$ & $\mathbf{1 0 0 . 0}$ \\
\hline
\end{tabular}

Source: Computed from survey, 2018

Governance services

The dominant value chain actors in playing regulation role are Coffee Standard and Quality Inspection Center (CSQIC) and Ethiopian commodity exchange (ECEX). They determine legal activities such as stabilizing market through inspection of quality and promotion of auction ground and determining level of prices for actors in the chain. Quality of Harar coffee is inspected in Dire Dawa Coffee Standard and Quality Inspection Center.

4.2.2. Opinion of respondents on the effectiveness of roles of actors in CVC

Under this section results of descriptive analysis regarding the effectiveness of the roles of actors such as input 
supply, availability of training, extension and financial services, and timeliness of information were discussed.

Table 12: Opinion of Respondents on the effectiveness of roles of actors in CVC

\begin{tabular}{|l|l|l|l|}
\hline \multirow{4}{*}{ Services } & Response & Frequency & Percent \\
\hline \multirow{5}{*}{ Availability of Input supply } & Effective & 90 & 31.0 \\
\cline { 2 - 4 } & Not effective & 201 & 69.0 \\
\cline { 2 - 4 } & Total & $\mathbf{2 9 1}$ & $\mathbf{1 0 0 . 0}$ \\
\hline \multirow{5}{*}{ Availability of Extension service } & Effective & 134 & 46.0 \\
\cline { 2 - 4 } & Not effective & 157 & 54.0 \\
\cline { 2 - 4 } & Total & $\mathbf{2 9 1}$ & $\mathbf{1 0 0 . 0}$ \\
\hline Timeliness of Market information & Effective & 99 & 34.0 \\
\cline { 2 - 4 } & Not effective & 192 & 66.0 \\
\cline { 2 - 4 } & Total & $\mathbf{2 9 1}$ & $\mathbf{1 0 0 . 0}$ \\
\hline \multirow{5}{*}{ Availability of credit services } & Effective & 64 & 22.1 \\
\cline { 2 - 4 } & Not effective & 227 & 77.9 \\
\cline { 2 - 4 } & Total & $\mathbf{2 9 1}$ & $\mathbf{1 0 0 . 0}$ \\
\cline { 2 - 4 } & Effective & 63 & 21.5 \\
\cline { 2 - 3 } & Not effective & 228 & 78.5 \\
\cline { 2 - 3 } & Total & $\mathbf{2 9 1}$ & $\mathbf{1 0 0 . 0}$ \\
\hline
\end{tabular}

Source: Computed from survey, 2018

Table 12 shows that, majority of respondents, $69.0 \%$ opined that the role of actors on supplying farm inputs such as coffee drying bed at required amount is not effective. The roles of actor in providing training were found out ineffective as opined by $54.0 \%$ of the respondents. The extension service given by actors was also found ineffective as opined by the $66 \%$ of the respondents.

The market information was provided to members as it was opined by $51 \%$ of the respondents (Table 11 ). However, it was found ineffective due to lack of timeliness of the information as it was argued by $77.9 \%$ of the respondents. Credit service also found out ineffective due to absence of interest free credit service as opined by $78.5 \%$ of the respondents. In this study availability of service indicates the availability of service by the required quantity.

4.2.3. Overall members' opinion on the effectiveness of roles of actors in CVC

Table 13: Opinion of Respondents on Overall effectiveness of roles of actors in CVC

\begin{tabular}{|l|l|l|}
\hline Members' Response & Frequency & Percent \\
\hline Effective & 93 & 32.0 \\
\hline Not effective & 198 & 68.0 \\
\hline Total & 291 & 100.0 \\
\hline
\end{tabular}

Source: Computed from survey, 2018

Table 13, shows that majority of the respondents, 198(68\%) argued that the roles of actors in CVC were not effective followed by 93(32\%) opined that the roles of actors in CVC were effective.

This result shows that majority of the respondents argued that the roles of actors in CVC were not effective. It is evident from previous analysis that farm inputs supply such as coffee drying bed is not available at required quantity, the market information provided to members was not up-to-date and not distributed at the right time. The credit service also was not interest free. All these factors led members express their opinion on the roles of actor in CVC as not effective.

\subsection{Linkage between Cooperatives and other Actors in the CVC}

Typically there are five main linkages between actors in the coffee value chain; namely, horizontal linkage, Vertical linkage, Technical Support Linkage, Business linkage and Marketing Linkage (figure 7). Results of FGD and KII on these five linkages was presented below followed by the results of the survey of the respondents on these linkages. 


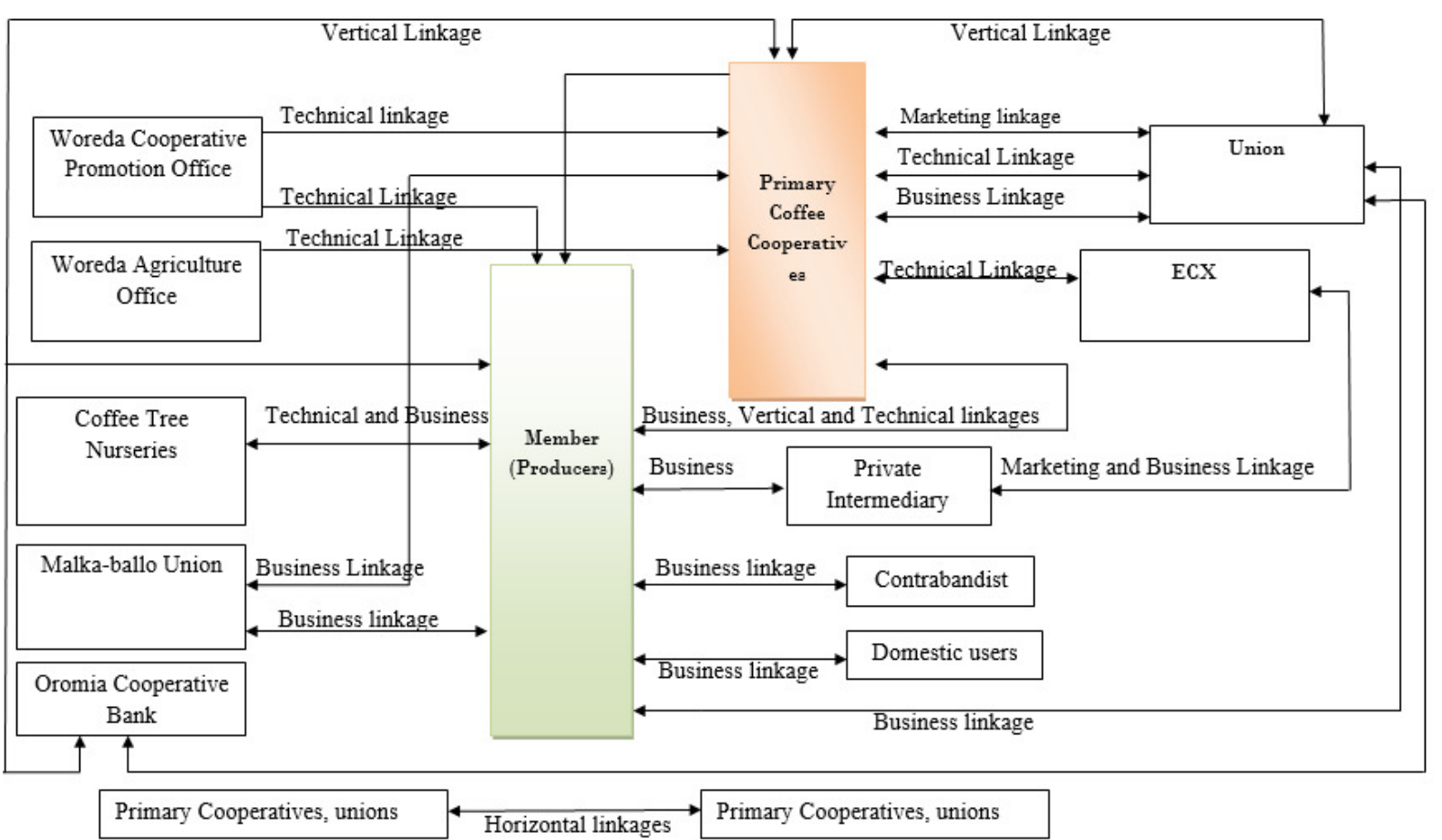

Figure 7: Types of Linkages between PCCs and other actors in the CVC

\subsubsection{Vertical and horizontal linkage}

Vertical linkage shows the formation of the primary cooperatives and the cooperative unions by their members farmers/producers and primary coops respectively. This shows two tier of cooperative formation. Figure 8 , below shows the two tier structure of a coop society. Since the primary cooperatives and unions are owned by farmers and primary cooperatives respectively, these two sets of institutions form an efficient, vertically integrated operation.

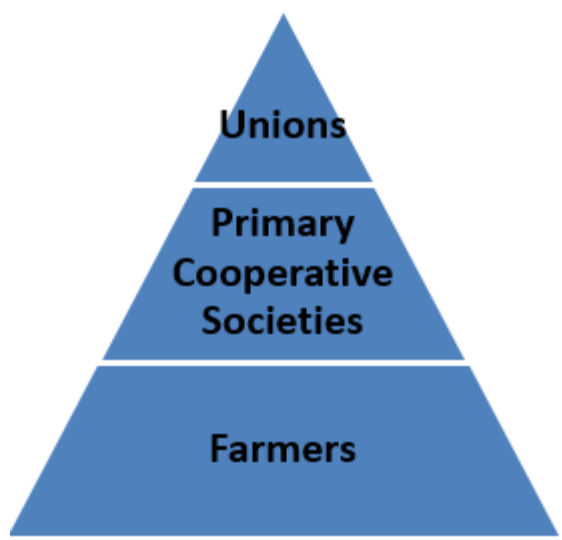

Figure 8: two tier cooperative societies' structure

The base of vertical linkage is farmers who come together and form primary cooperatives and thereby, primary cooperatives join together to form a cooperative union. The relationship has pyramid like shape. Producers gain strength by forming primary cooperatives whereas primary cooperatives gain strength by forming cooperative union. Thus, the aim of vertical linkage is to build capacity. For instance, through vertical linkage primary coffee cooperatives found in Melka-ballo woreda receive credit services from Oromia farmers' coffee union. Primary cooperatives on their turn give credit services to their members, i.e. farmer producers. In addition, the vertical linkage strengthened the coffee value chain to achieve quality production, efficient operations and market synergy. As discussion with KII indicated coffee processing machine installed by Melka-ballo union is a result of this linkage between the union and its members that is primary coffee cooperatives.

On the other hand, horizontal linkage is relationship between the same cooperative societies. Horizontal linkage is helpful in building cooperation between primary cooperatives or between unions.

\subsubsection{Technical Support Linkage}

Parallel to the vertical linkage, there is technical support linkage. Technical linkage is mostly relationship establishment between cooperative unions and its members. A good example is a relationship which found between 
Oromia farmers' coffee union and its members. Through this linkage the union represents its members and facilitates loan services from Oromia cooperative banks. This means the bank is given loan guarantee through the union. The result of the KII and FGD also indicated that the union undertakes some activities on behalf of its members, like assisting the coffee cooperatives in organic and fair-trade coffee certifications, continues improvements in coffee quality and quantity systems and performance needed to maintain certifications.

The other technical linkage is that found between woreda cooperative promotion office and PCCs, and between woreda agriculture office and member producers (coffee producers).

Technical linkage is mostly related to vertical linkage. They are the two faces of a coin. Technical supports like training, inviting members on experience sharing on coffee quality, auditing service, supervision, and others are also achieved through vertical linkage.

\subsubsection{Business linkage}

From the discussion with FGD and KII, it was clear that business linkage is the widest linkage found between almost all coffee value chain actors. As cooperative organizations are business entities, they have business relationship almost with all actors in the chain. The most existing business linkage is the one which found between PCCs and its members. This relationship is bilateral, means the members trade their coffee to the respective primary coffee cooperatives to which they are members. On the other hand, the PCCs trade/supply farm inputs to their members. The same linkage also exists between producers and cooperative union. For example, between Melka-ballo cooperative union and coffee producers in which producers sale their produces to the union and in turn the union supply farm inputs either through their respective cooperatives or directly through the union.

The other major business linkage is that of between PCCs and the union in which they engage in wide scope trade between themselves.

The linkage between coffee producers and private intermediaries and between coffee producers and contrabandists is also another important business linkage.

The other important business linkage is that of between Oromia Cooperative bank, and primary cooperatives and cooperative unions in which primary cooperatives and cooperative unions hold shares in the bank. All PCCs in Melka-ballo woreda, Melka-ballo cooperative union, Oromia coffee farmers' union are stakeholders of the Oromia cooperative bank. Each of them has shares value more than 50, 000 birr in the bank.

It should be noted that the double arrow in all linkages in the figure 8 above shows that the relationships is bilateral, i.e., two directional.

\subsubsection{Marketing Linkage}

In marketing linkage, cooperative unions play great role. Searching and creating the best market opportunity for members (PCCs) is the primary objective of the cooperative unions for which they were established. Among such cooperative unions Oromia coffee farmers' union is the outshining one. The union collects and processes members' produces and searches for best market, especially international markets and fetches them with best return that they never had before its establishment. Other marketing linkage also exists between cooperative unions and coffee producers, between PCCs and coffee producers and between cooperative unions and ECEX.

\subsubsection{Opinion of respondents on the degree of linkages between actors in CVC}

The degree of strength of the linkages in the coffee value chain varies between actors and it was measured on the 1, 2 and 3 level likert scales representing strong, medium and weak respectively (table 14).

Table 14: Opinion of Respondents on the Vertical Linkage between Different Actors

\begin{tabular}{|c|c|c|c|}
\hline Actors in the Chain & Strengthens of linkages & Frequency & Percent \\
\hline \multirow{4}{*}{$\begin{array}{l}\text { Vertical Linkage between PCCs and } \\
\text { Coffee Producers }\end{array}$} & Strong & 229 & 78.5 \\
\hline & Medium & 50 & 17.3 \\
\hline & Weak & 12 & 4.2 \\
\hline & Total & 291 & 100.0 \\
\hline \multirow{4}{*}{$\begin{array}{l}\text { Vertical Linkage between PCCs and } \\
\text { Cooperative Unions }\end{array}$} & Strong & 177 & 61.0 \\
\hline & Medium & 15 & 5.0 \\
\hline & Weak & 99 & 34.0 \\
\hline & Total & 291 & 100.0 \\
\hline \multirow{4}{*}{$\begin{array}{l}\text { Vertical Linkage between PCCs and } \\
\text { Oromia Cooperative Bank }\end{array}$} & Strong & 40 & 13.7 \\
\hline & Medium & 66 & 22.8 \\
\hline & Weak & 185 & 63.5 \\
\hline & Total & 291 & 100.0 \\
\hline \multirow{4}{*}{$\begin{array}{l}\text { Vertical Linkage between Cooperative } \\
\text { Unions and Oromia Cooperative Bank }\end{array}$} & Strong & 227 & 78.0 \\
\hline & Medium & 64 & 22.0 \\
\hline & Weak & 0 & 0.0 \\
\hline & Total & 291 & 100.0 \\
\hline
\end{tabular}

Source: Computed from survey, 2018 
Table 14 shows that more than three fourth of the respondents $229(78.5 \%)$ reported that there is strong Vertical Linkage between PCCs and Coffee Producers. Medium and weak vertical linkage was reported by $50(17.5 \%)$ and $12(4.5 \%)$ of the respondents. The Vertical Linkage between PCCs and Cooperative Unions also found strong as reported by majority of the respondents $177(61.0 \%)$. The rest of the respondents, $15(5 \%)$ and $99(34.0 \%)$ confirmed medium and weak vertical linkages. Contrary to this, there is weak Vertical Linkage between PCCs and Oromia Cooperative Bank as it was confirmed by majority of the respondents 185(63.5\%). The reason is that farmers who have shares in the Oromia cooperative Bank reported that they don't have any information about the bank. Even, they reported that they never received dividend. Strong and medium linkage was recorded by $40(13.7 \%)$ and $66(22.8 \%)$ of the respondents respectively. Regarding the Vertical Linkage between Cooperative Unions and Oromia Cooperative Bank, strong relationship was opined by 227(78.0\%) of the respondents. Whereas the rest $64(22.0 \%)$ of the respondents opined medium linkage.

On the other hand, opinions of respondents on horizontal linkage show that there is strong linkage between cooperatives in the value chain as opined by $63.5 \%$ of the respondents.

Table 15: Opinion of Respondents on the Technical Linkage between Different Actors

\begin{tabular}{|c|c|c|c|}
\hline Actors in the Chain & Strengthens of linkages & Frequency & Percent \\
\hline \multirow{4}{*}{$\begin{array}{l}\text { Technical linkage between Coffee } \\
\text { Producers and woreda Agriculture Office }\end{array}$} & Strong & 132 & 45.5 \\
\hline & Medium & 6 & 2.0 \\
\hline & Weak & 153 & 52.5 \\
\hline & Total & 291 & 100.0 \\
\hline \multirow{4}{*}{$\begin{array}{l}\text { Technical linkage between woreda } \\
\text { cooperative promotion Office and PCCs. }\end{array}$} & Strong & 226 & 77.6 \\
\hline & Medium & 65 & 22.4 \\
\hline & Weak & 0 & 0.0 \\
\hline & Total & 291 & 100.0 \\
\hline \multirow{4}{*}{$\begin{array}{l}\text { Technical linkage between cooperative } \\
\text { union and PCCs. }\end{array}$} & Strong & 94 & 32.4 \\
\hline & Medium & 35 & 12.0 \\
\hline & weak & 162 & 55.6 \\
\hline & Total & 291 & 100.0 \\
\hline \multirow{4}{*}{$\begin{array}{l}\text { Technical Linkage Between ECEX and } \\
\text { PCCs }\end{array}$} & Strong & 0 & 0.0 \\
\hline & Medium & 113 & 38.9 \\
\hline & weak & 178 & 61.1 \\
\hline & Total & 291 & 100.0 \\
\hline
\end{tabular}

Source: Computed from survey, 2018

As indicated in table 15, majority of the respondents, 153(52.5\%) opined that there is weak technical linkage between Coffee Producers and woreda Agriculture Office followed by 132(45.5\%) and 6(2.0\%) of respondents who reflected the linkage is strong and medium respectively. The survey result also indicated that there is strong technical linkage between woreda cooperative promotion Office and PCCs as witnessed by 226(77.6\%) of the respondents. Others $65(22.4 \%)$ indicated medium technical relationship between actors. With regard to Technical linkage between cooperative union and PCCs, weak technical support linkage was recorded as 162(55.6\%) of the respondents reported and $94(32.4 \%)$ of the respondents opined strong relationship. On the other hand, weak Technical Linkage was found Between ECEX and PCCs followed by medium linkage as opined by $178(61.1 \%)$ and $113(38.9 \%)$ of the respondents respectively. 
Table 16: Opinion of Respondents on the Business Linkage between Different Actors

\begin{tabular}{|c|c|c|c|}
\hline Actors in the Chain & Strengthens of linkages & Frequency & Percent \\
\hline \multirow{4}{*}{$\begin{array}{l}\text { Business Linkage between PCCS and } \\
\text { coffee producers }\end{array}$} & Strong & 192 & 66.0 \\
\hline & Medium & 95 & 32.8 \\
\hline & weak & 4 & 1.2 \\
\hline & Total & 291 & 100.0 \\
\hline \multirow{4}{*}{$\begin{array}{l}\text { Business Linkage between cooperative } \\
\text { unions and coffee producers }\end{array}$} & Strong & 148 & 51.0 \\
\hline & Medium & 143 & 49.0 \\
\hline & weak & 0 & 0.0 \\
\hline & Total & 291 & 100.0 \\
\hline \multirow{4}{*}{$\begin{array}{l}\text { Business Linkage between cooperative } \\
\text { unions and PCCs }\end{array}$} & Strong & 139 & 47.7 \\
\hline & Medium & 152 & 52.3 \\
\hline & weak & 0 & 0.0 \\
\hline & Total & 291 & 100.0 \\
\hline \multirow{4}{*}{$\begin{array}{l}\text { Business Linkage between Coffee } \\
\text { Producers and Retailers }\end{array}$} & Strong & 163 & 56.0 \\
\hline & Medium & 121 & 41.7 \\
\hline & Weak & 7 & 2.3 \\
\hline & Total & 291 & 100.0 \\
\hline \multirow{4}{*}{$\begin{array}{l}\text { Business Linkage between Coffee } \\
\text { Producers and Wholesalers }\end{array}$} & Strong & 154 & 53.0 \\
\hline & Medium & 92 & 31.7 \\
\hline & Weak & 45 & 15.3 \\
\hline & Total & 291 & 100.0 \\
\hline \multirow{4}{*}{$\begin{array}{l}\text { Business Linkage between Coffee } \\
\text { Producers and Contrabandists }\end{array}$} & Strong & 172 & 59.0 \\
\hline & Medium & 119 & 41.0 \\
\hline & Weak & 0 & 0.0 \\
\hline & Total & 291 & 100.0 \\
\hline
\end{tabular}

Source: Computed from survey, 2018

As shown in Table 16, strong business Linkage was reported between PCCS and coffee producers as opined by $172(66.0 \%)$ of the respondents followed by medium relationship $95(38.2 \%)$. The same business Linkage was reported between cooperative unions and coffee producers. Out of the total respondents 148(51.0\%) of them opined there is strong business linkage between cooperative unions and coffee producers whereas nearly half of the respondents opined $143(49.0 \%)$ the linkage is medium. With regard to business Linkage between cooperative unions and PCCs, medium linkage was reported by $152(52.3 \%)$ respondents while the remaining respondents 139(47.7\%) confirm strong linkage. With regard to Business Linkage between Coffee Producers and Retailers strong linkage was recorded by majority of the respondents163(56.0\%) while medium and weak linkage was reported by $121(41.7 \%)$ and $7(2.3 \%)$ of the respondents respectively. The same is true between Coffee Producers and Wholesalers. Strong business Linkage was reported between Coffee Producers and Wholesalers by majority of the respondents $154(53.0 \%)$ whereas $92(31.7 \%)$ and $45(15.3 \%)$ of the respondents opined medium and weak linkage. The other strong business Linkage reported was between Coffee Producers and Contrabandists as opined by $172(59.0 \%)$ of the respondents. And, 119(41.0\%) of the respondents opined medium linkage. This shows that still farmers are in the hands of private traders who want to exploit farmers' produces at lower price (retailers and contrabandists) as indicated by strong linkage between farmers and private traders. This should be minimized by increasing the linkage between cooperative societies and farmers/coffee producers. 
Table 17: Opinion of Respondents on the Marketing Linkage between Different Actors

\begin{tabular}{|c|c|c|c|}
\hline Actors in the Chain & Strengthens of linkages & Frequency & Percent \\
\hline \multirow{4}{*}{$\begin{array}{c}\text { Marketing Linkage between cooperative } \\
\text { unions and PCCs }\end{array}$} & Strong & 121 & 41.7 \\
\hline & Medium & 163 & 56.0 \\
\hline & Weak & 7 & 2.3 \\
\hline & Total & 291 & 100.0 \\
\hline \multirow{4}{*}{$\begin{array}{l}\text { Marketing Linkage between cooperative } \\
\text { unions and coffee producers }\end{array}$} & Strong & 104 & 35.6 \\
\hline & Medium & 30 & 10.4 \\
\hline & Weak & 157 & 54.0 \\
\hline & Total & 291 & 100.0 \\
\hline \multirow{4}{*}{$\begin{array}{l}\text { Marketing Linkage between PCCs and } \\
\text { coffee producers }\end{array}$} & Strong & 0 & 0.0 \\
\hline & Medium & 123 & 42.2 \\
\hline & Weak & 168 & 57.8 \\
\hline & Total & 291 & 100.0 \\
\hline \multirow{4}{*}{$\begin{array}{l}\text { Marketing Linkage between cooperative } \\
\text { unions and ECEX }\end{array}$} & Strong & 0 & 0.0 \\
\hline & Medium & 116 & 40.0 \\
\hline & Weak & 175 & 60.0 \\
\hline & Total & 291 & 100.0 \\
\hline
\end{tabular}

Source: Computed from survey, 2018

In the table 17, medium marketing linkage was recorded between cooperative unions and PCCs as witnessed by more than half of the respondents $163(56.0 \%)$. Strong and weak marketing linkage was reported by $121(41.7 \%)$ and $7(2.3 \%)$ of the respondents respectively. The marketing linkage between cooperative unions and coffee producers, between PCCs and coffee producers and between cooperative unions and ECEX was found weak as reported by $157(54.0 \%), 168(57.8 \%)$ and $175(60.0 \%)$ of the respondents respectively.

4.3.6. Opinion of Respondents on Overall Linkages between PCCs and Other Actors in the CVC

Overall linkages between actors in the coffee value chain refer to the overall degree of strength of the linkages between all actors in the coffee chain. Table 18 below presents opinion of respondents on overall linkages between actors in the coffee chain as strong, medium or weak.

Table 18: Opinion of Respondents on Overall linkages between actors

\begin{tabular}{|l|l|l|}
\hline Linkage Response & Frequency & Percent \\
\hline Strong & 65 & 22.4 \\
\hline Medium & 57 & 19.6 \\
\hline Weak & 169 & 58.0 \\
\hline
\end{tabular}

Source: Computed from survey, 2018

Table 18, shows that majority of the respondents, $169(58.0 \%)$ opined that the linkage between their cooperative societies and other actors is weak followed by $57(19.6 \%)$ who confirmed that the linkage is medium and the rest $65(22.4 \%)$ of the respondents opined that the linkage is strong.

\subsection{Analysis of Determining factors affecting the Effectiveness of Cooperatives in CVC}

\subsubsection{Multicollinearity Diagnosis}

Before running the model, all hypothesized explanatory variables were checked for the existence of multicollinearity problem. There are two measures that are often suggested to test the existence of multicollinearity. These are: Variance Inflation Factor (VIF) for association between the continuous explanatory variables and Contingency Coefficients (CC) for discreet explanatory variables. The technique of VIF is used to detect the problem of multicollinearity between the continuous variables. According to Maddala (1992), VIF can be defined as: $\mathrm{VIF}(\mathrm{Xi})=1 / 1-\mathrm{R}^{2}$ Where $\mathrm{Ri}^{2}$ is the squared multiple correlation coefficient between $\mathrm{Xi}$ and the other explanatory variables. The highest the value of VIF (Xi) the more difficult or collinear the variable Xi is. As a rule of thumb, if the VIF of an explanatory variable greater than 10, there is a multicollinearity problem. Coefficient of Contingency, on the other hand, is computed to detect the problem of multicollinearity between predictor variables. The contingency coefficient is computed as (Karl, cited in Gupta, 2001):

$\mathrm{C}=\sqrt{\frac{\psi^{2}}{n+\psi^{2}}}$

Where $\mathrm{C}$ is coefficient of contingency, $\psi^{2}$ is chi square test, and $\mathrm{n}$ is total sample size. The value of $\mathrm{C}$ ranges from 0 to 1 , and a value approaching to 1 signifies that there is strong association between the predictor variables and vice versa.

In this study, all explanatory variables are discrete variables. So, only Ccontingency coefficient (CC) was computed to detect the problem of multicollinearity between discrete predictor variables. Accordingly, the test of 
multicollinearity for discrete explanatory variables in this study shows weak association between predictor variables (Appendix 1).

In general, the Statistical software called the statistical package for social science (SPSS) version 20.0 was used to compute $\mathrm{CC}$ and to analyze the collected data at $95 \%$ confidence level.

\subsubsection{Omnibus Tests of Model Coefficients}

Table 19: Omnibus Tests of Model Coefficients

\begin{tabular}{|l|l|l|l|l|}
\hline \multirow{2}{*}{ Step 1 } & & Chi-square & df & Sig. \\
& Step & 148.604 & 8 & .000 \\
\cline { 2 - 5 } & Block & 148.604 & 8 & .000 \\
\cline { 2 - 5 } & Model & 148.604 & 8 & .000 \\
\hline
\end{tabular}

Source: Computed from survey, 2018

The omnibus tests of model coefficient in the last iteration shows that the addition of each variable into the model is statistically significant since the P-value (Sig.) of the model, which is 0.000 , is less than cutoff value of 0.05 (see Table 19).

\subsubsection{Tests of Goodness Fit of the Model}

Hosmer and Lemeshow test was used to accept or reject the null hypothesis "the model does not adequately describe the data". If the significance level of the test is less than 0.05 , the null hypothesis is not rejected and the alternative hypothesis which signifies the adequacy of the model to describe the data is rejected.

\section{Table 20: Hosmer and Lemeshow Test}

\begin{tabular}{|l|l|l|l|}
\hline Step & Chi-square & Df & Sig. \\
\hline 1 & 5.563 & 8 & 0.696 \\
\hline
\end{tabular}

Source: Computed from survey, 2018

However, in this study, since $\psi^{2}(8, \mathrm{~N}=291)=5.563$ and its $\mathrm{P}$-value (Sig.) $=0.696$, the null hypothesis was rejected by justifying the model is statistically significant to adequately describe the data (see Table 20)

\subsubsection{Classification Table}

The classification table shows the percentage of observed cases that are correctly or incorrectly classified.

Table 21: Classification Table

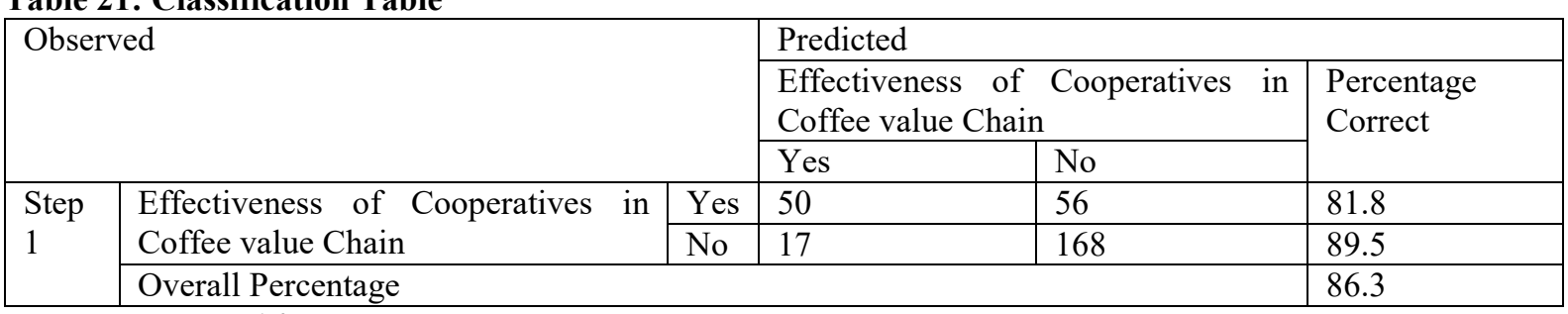

Source: Computed from survey, 2018

Table 21 shows that the model is able correctly to classify 81.8 percent of those members of the cooperatives who agreed that their cooperative is effective in CVC and 89.5 percent who disagreed, for an overall success of 86.3 percent.

\subsubsection{Model Summary}

Table 22: Model Summary

\begin{tabular}{|l|l|l|l|}
\hline Step & -2 Log likelihood & Cox \& Snell R Square & Nagelkerke R Square \\
\hline 1 & $75.212^{\mathrm{a}}$ & 0.544 & 0.732 \\
\hline
\end{tabular}

Source: Computed from survey, 2018

The model summary shown on Table 22 above showed that the likelihood of the explanatory variables included in the model to explain the dependent variable. Accordingly, the Cox \& Snell R Square and the Nagelkerke R Square indicated that $54.4 \%$ to $73.2 \%$ of the variation in the dependent variable (effectiveness of cooperatives in $\mathrm{CVC}$ ) is due to the explanatory variables.

\subsubsection{Results of Binary Logistic Regression Model}

Logistic regression analysis was employed to predict the probability with which each of the predictor variables considered contributes to effectiveness of cooperatives in coffee value chain. The model contained 13 independent variables (Training, Corruption, Management Capacity, Technology, Market Information, Input Supply, Processing, Timeliness in delivery, Transport facility, Storage facility, Proximity to cooperative, Access to Credit and Pricing). The full model containing all predictors was statistically significant, $\chi 2(8, \mathrm{~N}=291)=148.604$, $\mathrm{p}<.001$, indicating that the model was able to distinguish between respondents who witnessed and denied the effectiveness of cooperatives in coffee value chain. The model as a whole explained between $54.4 \%$ (Cox and Snell R square) and $73.2 \%$ (Nagelkerke R squared) of the variance in effectiveness of cooperatives in coffee value chain, and correctly classified 86.3 percent of cases. 
Table 23 below shows the logistic regression coefficients (B), the standard errors (S.E.), the Wald $\psi^{2}$ statistic, associated $\rho$-values (Sig.) and odds ratio $(\operatorname{Exp}(\beta))$ for each of the predictor variables. Accordingly, the statistical significance and results of the effects of each of the predictor variables are discussed below. In this study the Wald statistic was used to test the unique contribution of each predictor variable holding constant the other variables. By employing 0.05 criterion of statistical significance, out of 13 variables included in the model only 6 of them has significant effect on the effectiveness of cooperatives in coffee value chain. Accordingly, corruption (CORRUP), Training (TRAININ) and Management capacity (MNGTCAPP) were significant at p-value less than 0.01; Technology (TECHNO), Access to credit (ACCETOCRED) and Proximity to cooperative (PROXIMITY) were significant at less than 0.05 . The partial influence of each statistically significant predictor variables were analyzed by using the odds ratio in the logistic regression.

Table 23: Binary Logistic Regression Result of Partial Effect of Predictor Variables

\begin{tabular}{|l|l|l|l|l|l|l|l|}
\hline \multicolumn{2}{|c}{} & B & S.E. & Wald & Df & Sig. & Exp(B) \\
\hline \multirow{3}{*}{$1^{\text {a }}$} & CORRUP & -2.972 & .969 & 9.401 & 1 & $.002^{* *}$ & .051 \\
\cline { 2 - 8 } & TECHNO & -2.958 & 1.109 & 7.119 & 1 & $.008^{* *}$ & .052 \\
\cline { 2 - 8 } & INPUSUPP & .202 & .482 & .177 & 1 & .674 & 1.224 \\
\cline { 2 - 8 } & MARKINFO & .678 & .602 & 1.265 & 1 & .261 & 1.969 \\
\cline { 2 - 8 } & ACCETOCRED & .528 & .253 & 4.340 & 1 & $.037 *$ & 1.695 \\
\cline { 2 - 8 } & PRICING & 8.529 & 23127.815 & .000 & 1 & 1.000 & 5058.197 \\
\cline { 2 - 8 } & TRANSFAC & 27.622 & 7669.057 & .000 & 1 & .997 & .000 \\
\cline { 2 - 8 } & STORAFAC & .614 & .396 & 2.409 & 1 & .121 & 1.849 \\
\cline { 2 - 8 } & PROCESS & -.407 & .745 & .298 & 1 & .585 & .666 \\
\cline { 2 - 8 } & TRAININ & 3.293 & .957 & 11.836 & 1 & $.001^{* *}$ & 26.934 \\
\cline { 2 - 8 } & PROXIMITY & -1.553 & .660 & 5.546 & 1 & $.019^{*}$ & .212 \\
\cline { 2 - 8 } & MNGTCAPP & 3.650 & .877 & 17.316 & 1 & $.000^{* *}$ & 38.474 \\
\cline { 2 - 8 } & TIMELYDEL & 1.883 & 1.016 & 3.433 & 1 & .064 & 6.575 \\
\cline { 2 - 8 } & Constant & 18.696 & 21819.290 & .000 & 1 & .999 & $1.318 \mathrm{E} 8$ \\
\hline
\end{tabular}

Source: Computed from survey, 2018

Table 23 presents partial effect of predictor variables on dependent variable. Exp ( $($ ) shows the odds ratio associated with each predictor variable. The odds ratio of 1 indicates that the predictor variable has no influence on dependent variable (effectiveness of coffee cooperatives in coffee value chain). This means that the two variables are statistically independent. The odds ratio greater than 1 indicates that the two variables are statistically dependent or predictor variable has positive influence on dependent variable.

The value of odds ratio less than 1 indicates that the two variables are statistically dependent and predictor variable has negative influence on dependent variable. From the table above the strongest predictors of the effectiveness of cooperatives in coffee value chain were Corruption, Technology, Access to credit, Training, Proximity to Cooperative and Management Capacity by recording odds ratio (Exp(B)) of 0.051, 0.052, 1.695, 26.934, 0.212 and 38.474 respectively. Among those strongest predictors only three of them (Access to credit, Training and Management Capacity) have positive impact on dependent variable (see regression coefficient under column B of the table above), whereas the remaining three variables (Corruption, Technology and Proximity to Cooperative) have negative impact on the dependent variable "effectiveness of coffee cooperatives in coffee value chain". The thorough discussion and interpretation of each strongest predictor variables are as follows.

Corruption (CORRUP):- It is a practice of getting a benefit without legal procedure. This variable was hypothesized to influence the effectiveness of cooperatives in coffee value chain negatively. As corruption increase effectiveness of cooperatives in coffee value chain decrease. The p-value (Sig.) for corruption (CORRUP) is 0.002 indicates that it is statistically significant predictor variable which has negative effect (its Exp(B) is less than) on effectiveness of cooperatives in coffee value chain. This indicates that the increase of corruption level will result in the decrease of effectiveness of cooperatives in coffee value chain. Its Exp (B) value 0.051 signifies that there is strong negative relationship between the predictor variable corruption and effectiveness of cooperatives in coffee value chain. Therefore the hypothesized statement which states that the increase in corruption will be the decrease in effectiveness of cooperatives in coffee value chain is not rejected since a level increase in corruption has decreased the likelihood that effectiveness of cooperatives in coffee value chain is decreased by a factor of 0.051 .

Technology (TECHNO):- Refers to the use of new and improved materials, tools, and techniques, to make farm work easier or more pleasant and more productive. It was hypothesized that the use of improved and new technology increases the coffee production efficiency and thereby influence the effectiveness of cooperatives in coffee value chain positively. Its p-value 0.008 indicates that this variable is statistically significant predictor variable which has negative impact (its $\operatorname{Exp}(B)$ is less than 1) on the effectiveness of cooperatives in coffee value chain. Its Exp (B) value, 0.052, is less than 1, indicating that for every additional use of new and improved technology the likelihood of cooperatives to become effective in coffee value chain decrease by a factor of 0.052 . 
Therefore the hypothesized statement which states that the more increase in use of technology the more will be the increase in effectiveness of cooperatives in coffee value chain is rejected since a unit increase in the use of technology has decreased the likelihood of effectiveness of cooperatives by a factor of 0.052 . This shows that even if use of technology by farmers increases, effectiveness of cooperatives in coffee value chain is decreased since the new technology is expensive, and not available at required quantity and time.

Access to credit (ACCES):- Refers to the ease of getting credit service. It was hypothesized that this variable influences the effectiveness of cooperatives in coffee value chain. This variable is statistically significant at $p$ value 0.037 . This indicates that it is statistically significant predictor variable, which has a positive influence on the effectiveness of cooperatives in coffee value chain. Its $\operatorname{Exp}(\beta)$ value 1.695 indicates that there is positive relationship between access to credit and effectiveness of cooperatives in coffee value chain. However, the result of descriptive analysis indicated that this predictor variable is not effective in coffee value chain due to absence of interest free credit. Therefore the hypothesized statement which states that the more access to credit the more effectiveness of cooperatives in coffee value chain is not rejected since a unit increase in to credit access has increased the likelihood effectiveness of cooperatives in coffee value chain by a factor of 1.695 .

Training (TRAININ):- It is one of the statistically significant predictor variable influencing effectiveness of cooperatives in coffee value chain at p-value 0.001. Its Exp (B) value which is 26.934 indicates that it is a useful strong predictor of the effectiveness of cooperatives in coffee value chain. The odd ratio indicates that there is positive relationship between predictor variable (training) and dependent variable (effectiveness of cooperatives in coffee value chain). Therefore, the hypothesized statement which states that the more trainings provided to board, members and employees of cooperatives and other actors in the coffee value chain the more will be the effectiveness of cooperatives in coffee value chain is not rejected since a unit increase in training has increased the likelihood effectiveness of cooperatives in coffee value chain by a factor of 26.934 . However, the result of descriptive analysis showed that the training given to members was not effective due to its unavailability to all members.

Proximity to Cooperative (PROXI):- Refers to the distance between members` residence and cooperative and measured in terms of kilometer. It was expected that this variable influence effectiveness of cooperatives negatively. It is one of statistically significant predictor variable at p-value 0.019 . This indicates that there is statistically significant negative relationship between distance from cooperative center and dependent variable (effectiveness of cooperatives in coffee value chain). Its $\operatorname{Exp}(\mathrm{B})$ value 0.212 signifies that there is strong negative association between the predictor variable (distance from cooperative) and dependent variable (effectiveness of cooperatives in coffee value chain). Therefore the hypothesized statement which states that the more distance between members' residence and cooperative the less will be the effectiveness of cooperatives in coffee value chain is not rejected since a unit increase in distance between members ' residence and cooperative has decreased the likelihood of effectiveness of cooperatives in coffee value chain by a factor of 0.212 .

Management Capacity (MNGTCAPP):- Refers to employing qualified, honesty and dedicated staffs. This variable was assumed to influence effectiveness of cooperatives in coffee value chain positively. Its p-value 0.001 indicates that it is statistically significant predictor variable, which has a positive impact on effectiveness of cooperatives in coffee value chain. Its Exp (B) value 38.474 signifies that there is strong positive association between qualified employees (manager) and effectiveness of cooperatives in coffee value chain. Therefore the hypothesized statement which states that the more qualified employee/manger is hired the more will be the effectiveness of cooperatives in coffee value chain is not rejected since a unit increase in the quality/capacity of employees has increased the likelihood of the effectiveness of cooperatives in coffee value chain by a factor of 38.474

\section{CHAPTER FIVE}

\section{SUMMARY OF FINDINGS, CONCLUSION AND RECOMMENDATIONS}

This chapter summarizes findings and concludes the interpretation of the data analysis and gives recommendations of the study of effectiveness of the coffee value chain conducted in Melka-ballo Woreda, Oromia National regional state with a special reference to Coffee cooperatives.

\subsection{Summary of Findings}

In this study, attempt has been made to identify actors in the coffee value chain and describe their roles, to examine the linkages between cooperatives and other actors in the coffee value chain, and analyze determining factors affecting the effectiveness of cooperatives in coffee value chain in Melka-ballo woreda. In order to describe actors and identify their roles in the coffee value chain, to examine the linkages between coffee cooperatives and other actors in the coffee value chain and to analyze determining factors affecting the effectiveness of cooperatives in coffee value chain, primary data were collected from 291 member respondents randomly selected from three PCCs and focus group discussions (FGD) and key informant interviews (KII) were also conducted with 34 people having direct and indirect relationship with the activities of coffee value chain. 
Data collected regarding actors and their roles in the CVC, and the linkages between cooperatives and other actors in the CVC were analyzed by using descriptive statistics. Data collected regarding determining factors affecting the effectiveness of cooperatives in CVC was analyzed using econometric model, i.e. binary logistic regression.

\subsubsection{Findings of Demographic Characteristics of the Respondents}

To describe respondents by their demographic characteristics, the survey result shows that majority of respondents $173(59.5 \%)$ were male and $163(56.0 \%)$ of respondents were young. As to the educational level of member respondents majority of the respondents $177(61.0 \%)$ were literate, or minimum they can read and write. From the total respondents $279(96.0 \%)$ were married and also $137(47.0 \%)$ respondents were with medium size family.

\subsubsection{Findings of Actors and Their Roles in the CVC}

In the study area, there are primary and supportive actors currently involving in CVC. The primary actors are those involved in commercial activities and include coffee seedling nurseries, coffee producers, primary cooperatives, cooperative unions, private intermediaries (retailers and wholesalers), exporters, contrabandists and local users. The supportive actors are those who provide supportive services and include woreda cooperative promotion office, woreda Agriculture and Rural Development Office, Primary coffee cooperatives, cooperative unions, Oromia Cooperative Bank (OCB), Coffee Standard and Quality Inspection Center (CSQIC), Ethiopian commodity exchange (ECEX) and NGOs are main supporting actors who play a central role in the provision of different services in Melka-ballo CVC.

Supplying farm inputs such as coffee drying bed, providing services like training and extension, market information and credit were indicated as major roles which these actors contribute in the CVC in Melka-ballo woreda. Some roles are performed by more than one actor, and some actors perform more than one role.

The survey result indicated that the role of actors on supplying farm inputs such as coffee drying bed at required amount is not effective. The roles of actor in providing training were found out ineffective as opined by $54.0 \%$ of the respondents. The extension service given by actors was also found ineffective as opined by the $66 \%$ of the respondents. The market information was provided to members as it was opined by $51 \%$ of the respondents. However, it was found ineffective due to lack of timeliness of the information as it was argued by $77.9 \%$ of the respondents. Credit service also found out ineffective due to absence of interest free credit service.

With regard to respondents' overall opinion on the roles of actors, majority of the respondents, 198(68\%) argued that the roles of actors in CVC were not effective. It is evident from previous analysis that farm inputs supply such as coffee drying bed is not available at required quantity, the market information provided to members was not up-to-date and not distributed at the right time. The credit service also was not interest free. All these factors led members express their opinion on the roles of actor in CVC as not effective.

\subsubsection{Findings of Linkages between Cooperatives and Other Actors in the CVC}

* Typically five main linkages namely; Horizontal linkage, Vertical linkage, Technical Support Linkage, Business linkage and Marketing Linkage were found between actors in the coffee value chain.

* Strong Horizontal linkage was found between cooperative societies at the same level as supported by $63.5 \%$ of the respondents.

* From the total respondents, 229(78.5\%) reported that there is strong Vertical Linkage between PCCs and Coffee Producers. The Vertical Linkage between PCCs and Cooperative Unions also found strong as reported by majority of the respondents $177(61.0 \%)$. Weak Vertical Linkage was recorded between PCCs and Oromia Cooperative Bank as opined 185(63.5\%) of the respondents. Regarding the Vertical Linkage between Cooperative Unions and Oromia Cooperative Bank, strong relationship was reported as opined by $227(78.0 \%)$ of the respondents.

* Regarding Technical support linkage between Coffee Producers and woreda Agriculture Office weak linkage was recorded by majority of respondents, $153(52.5 \%)$. The survey result indicated that there is strong Technical support linkage between woreda cooperative promotion Office and PCCs as witnessed by $226(77.6 \%)$ of the respondents. On the other hand, weak Technical Linkage was found between cooperative union and PCCs and between ECEX and PCCs as opined by 162(55.6\%) and 178(61.1\%) of the respondents respectively.

* As far as business Linkage between PCCS and coffee producers and between cooperative unions and coffee producers strong relationship was recorded by $172(66.0 \%)$ and $148(51.0 \%)$ of the majority of the respondents respectively. The same business linkage was also indicated between Coffee Producers and private intermediaries (wholesalers, retailers and contrabandists). Out of total respondents, 154(53.0\%), $163(56.0 \%)$ and $172(59.0 \%)$ of them opined strong business linkage between Coffee Producers and Wholesalers, between Coffee Producers and Retailers and between Coffee Producers and Contrabandists respectively. With regard to business Linkage between cooperative unions and PCCs, medium linkage was reported by $152(52.3 \%)$ of the respondents.

* The marketing linkage between cooperative unions and coffee producers, between PCCs and coffee producers and between cooperative unions and ECEX was found weak as reported by 157(54.0\%), $168(57.8 \%)$ and $175(60.0 \%)$ of the respondents respectively. Only medium marketing linkage was 
recorded between cooperative unions and PCCs as witnessed by more than half of the respondents $163(56.0 \%)$.

\subsubsection{Findings on Overall Linkages between Cooperatives and Other Actors in the CVC}

The survey result show that the overall linkage between coffee cooperatives and other actors in the CVC is weak as confirmed by the majority of the respondents, $169(58.0 \%)$.

\subsubsection{Findings of Determining factors affecting the Effectiveness of Cooperatives in CVC}

Binary logistic regression was used to analyze determining factors affecting the effectiveness of cooperatives in coffee value chain. The interpretation from the result of binary logistic regression gives a good understanding of the effect of variables influencing the effectiveness of cooperatives in coffee value chain. The Cox \& Snell $\mathrm{R}$ Square and the Nagelkerke R Square was used to measure the proportion of the total variation of the dependent variable explained by the predictor variables. Accordingly, in this study 73.2 percent of the variation in the dependent variable "effectiveness of cooperatives in coffee value chain" was explained by the variance in the predictor variables. Out of thirteen predictor variables included in the model it was found out that only six of them have statistically significant partial effect on the dependent variable "effectiveness of cooperatives in coffee value chain". Accordingly, Corruption, Technology, Access to credit, Training, Proximity to Cooperative and Management Capacity were found that they have statistically significant effect on dependent variable "effectiveness of cooperatives in coffee value chain at 0.05 significant level. From total statistically significant predictor variables four were significant at $p$-value less than 0.01 whereas two are significant at $p$-value less than 0.05. Out of these statistically significant variables three of them have positive partial effect and three of them have negative partial effect on the dependent variable "effectiveness of cooperatives in coffee value chain". Accordingly, Access to credit, Training, and Management Capacity have partial positive effect on dependent variable "effectiveness of cooperatives in coffee value chain" whereas, Corruption, Technology and Proximity to Cooperative society have negative partial effect on dependent variable "effectiveness of cooperatives in coffee value chain".

\subsection{Conclusion}

The focus of this thesis was to study the effectiveness of cooperatives in Coffee value chain in Melka-ballo woreda, East Hararghe Zone, Oromia Regional State, Ethiopia. Based on the realization of specific objectives of the study the following conclusion was drawn from data analysis and interpretation;

In the study area, there are direct and indirect/supportive actors currently involving in CVC. The primary actors are those involved in commercial activities and include coffee seedling nurseries, coffee producers, primary cooperatives, cooperative unions, private intermediaries (retailers and wholesalers), exporters, contrabandists and local users. The supportive actors are those who provide supportive services and include woreda cooperative promotion office, woreda Agriculture and Rural Development Office, Primary coffee cooperatives, cooperative unions, Oromia Cooperative Bank (OCB), Coffee Standard and Quality Inspection Center (CSQIC), Ethiopian commodity exchange (ECEX) and NGOs are main supporting actors who play a central role in the provision of different services in Melka-ballo coffee value chin.

Supplying farm inputs, providing services like training and extension, market information and credit were concluded as major roles which these actors perform in the CVC in Melka-ballo woreda. The roles which are performed by these actors like supplying farm inputs, providing services such as training and extension, market information and credit are not effective.

Based on respondents' overall opinion on the roles of actors, it was concluded that the roles of these actors are not effective. Lack of coffee drying bed at required quantity, absence of training and extension at required quantity, provision of outdated market information and absence of interest free credit service are some reasons for the ineffectiveness of the roles of actors in the CVC in Melka-ballo woreda.

There are five main linkages between actors in CVC namely; Horizontal linkage, Vertical linkage, Technical Support Linkage, Business linkage and Marketing Linkage. There is Strong horizontal linkage between cooperative societies at the same level.

With regard to vertical linkage, strong linkage existed between all actors except Vertical Linkage between PCCs and Oromia Cooperative Bank which is weak. So, it is advisable to conclude that strong vertical linkage existed between actors leading to more effectiveness of the CVC. From survey result, weak technical support linkage was reported between actors in the chain except, strong technical linkage between woreda cooperative promotion Office and PCCs as witnessed by 226(77.6\%) of the respondents. So, the researcher concluded that there is weak technical support linkage between actors leading to less effectiveness of the coffee value chain. The survey result show strong business linkage between coffee producers and private traders (Wholesalers, Retailers and Contrabandists) which shows that still farmers are in the hands of intermediaries who want to exploit farmers' produces with low price. To change the condition and maintain the effectiveness of CVC, cooperative societies should outrun private intermediaries and diminish the linkage between coffee producers and private traders. There is weak marketing linkage between cooperative unions and coffee producers, between PCCs and coffee producers 
and between cooperative unions and ECEX as reported by $157(54.0 \%), 168(57.8 \%)$ and $175(60.0 \%)$ of the respondents respectively. This shows that the dissemination of market information between actors is ineffective. The market information distribution channel is obsolete and the information is not timely. The result of the descriptive statistics showed that there was weak linkage among chain actors.

Corruption, Technology, Access to credit, Training, Proximity to Cooperative and Management Capacity are critical factors affecting effectiveness of cooperatives in Coffee value chain.

In general, it was found that majority of the members confirmed that the coffee value chain is not effective. So, it is possible to make the coffee value chain more effective and result oriented by way of taking proper measures as recommended in the following section.

\subsection{Recommendations}

Based on the findings of the study, the following points are recommended for consideration to make the coffee value chain more effective.

Since the strength of the linkage among chain actors is one of the most determining factors for the effectiveness of the coffee value chain greater attention should be given by all stakeholders to design strategies on how to smooth their relationship and avoid any bottlenecks such as corruption, inefficient management, poor quality training and improve service providing system, providing simple and cheap technology (example, portable coffee drying bed), improving coffee quality from production to post harvest by giving training to members/producers, expanding irrigation services, designing interest free credit services, providing timely market information, hiring experienced and competent manger for cooperatives and shortening the distance between members and cooperative societies.

Corruption, lack of integrity or honesty of committee members and employees is strong factor significantly influencing the effectiveness of coffee value chain. To get effective chain it is compulsory to abolish corruptive practices. Such corruptive practices should be diminished by giving awareness about the effect of corruption and dismissing corrupted members of the committees and fire of employees with such characteristics. Care should be given while recruiting members of committees and employees by focusing on their background and ethical standards.

Lack of Credit is another important variable significantly influencing the effectiveness of coffee value chain. Thus, sufficient and interest free credit facilities should be available in a timely manner to cooperative members. Microfinance institutions play a crucial role in this regard and strategies should be designed to link microfinance with the cooperatives and appropriate repayment arrangement should be negotiated in line with the businessfinancing requirement of the members of the cooperatives.

Proximity to cooperatives is one of the variables influencing effectiveness of cooperatives in Coffee value chain. To make the chain more effective coffee cooperatives have to use different mechanisms which can reduce the distance between cooperatives and members` residence. To do these PCCs must procure members`output at farm level, provide transportation service and distribute input services at village/Keble level.

Training is another very important factor influencing effectiveness of coffee value chain. Coffee producers should get training related to production, quality (sorting, grading, storing), marketing, etc. coffee cooperatives being with other actors in the chain should extend such training not only to boards/committees and employees but also to members. This could be done in collaboration with other service providers and NGOs that deliver such kind of training in a more professional and adequate manner.

Management capacity is another variable influencing effectiveness of the chain whether or not PCCs have business and marketing oriented leadership. The leaders of PCCs should be well equipped in doing business and competing in the market. Cooperative leaders such as board and different committees should get training related to leadership, change management, planning, organizing, evaluation, and tec. Entrepreneurship training related with opportunity seeking and exploitation, goal setting, innovation and risk taking should be given to leaders and employees of PCCs. Cooperatives should hire competent and experienced manager who has business and market skills.

Access to simple and new technology is also a very important variable affecting the effectiveness of the chain. Introducing farmers to simple technologies which may save cost and time was believed to enhance the effectiveness of chain. Efforts have to be made in introducing cost effective farm mechanization including, coffee collecting and drying bed, appropriate warehouse preparation and development of a viable marketing strategy and to link farmers to the market.

Therefore, the effectiveness of cooperatives in the coffee value chain is based on how effectively all stakeholders and actors in the coffee value chain are working together. All actors should work together in a more synergetic way to maximize the effectiveness of the coffee value chain of coffee cooperatives and ensure the sustainability of cooperative societies in Melka-ballo woreda. 


\section{Reference}

AAFC (Agriculture and Agri-Food Canada), 2004. Value-added agriculture in Canada. Report of the standing senate committee on agriculture and forestry 2004, Agriculture and Agri-Food, Canada.

Abraham Tegegn (2013). Value Chain Analysis of Vegetables: The Case Of Habro And Kombolcha Woredas In Oromia Region, Ethiopia :Haramaya University

Akiyama, T., (2001), "Coffee Market Liberalization since 1990." in Akiyma, T.,J. Baffes, D.Larson and B.Varangis, Commodity Markets Reforms: Lessons of two decades. Washington D.C.: World Bank Publications.

Alebel et al., (2010). A Study on the Formulation of Policy Options and Strategies to Enhance the Participation of Producers, Traders and Processors in the Grain Market of the Ethiopia Commodity Exchange. Final Research Report of Ethiopian Development Research Institute.

Anandajayasekeram, P. and Berhanu Gebremedhin, 2009. Integrating innovation systems perspective and value chain analysis in agricultural research for development: implications and challenges. Improving Productivity and Market Success (IPMS) of Ethiopian farmers project working paper 16. ILRI (International Livestock Research Institute), Nairobi, Kenya.

Bammann, H., 2007. Participatory value chain analysis for improved farmer incomes, employment opportunities and food security. Pacific Economic Bulletin, 22,(3):125.

Bezabah Emana, 2008. Value chain analysis of horticultural crops in Kombolcha districts of eastern Oromia Region, Ethiopia. A study conducted for Action Aid Ethiopia, Addis Ababa.

Birhanu Beshah, et al, (2013). Quality and Value Chain Analyses of Ethiopian Coffee: Journal of Agriculture and Social Research, Vol. 13, No.2.

Bryceson, K and J. Kandampully, 2004. The balancing act: "E" issues in the Australian agri-industry sector. Proceedings of the McMaster World Congress on the Management of Electronic Business, 14-16 Jan 2004, Hamilton, Ontario.

Campbell and Ruth. (A Value-Chain Approach to Coffee Production): Linking Ethiopian Coffee Producers to International Markets.

CIAT (Centro International de Agricultureal Tropical), 2004. Increasing the competitiveness of market chains of smallholder's producers. Manual, 3: Territorial Approach to Rural Agro Enterprise Development Project.

Demeke Tilahun (2007). Performance of Coffee Marketing Co-Operatives And Members' Satisfaction in Dale District, Snnprs-Southern Ethiopia. M.Sc. Thesis. Haramaya University

Dendena Getachew, Efrem Lema and Lema Belay, 2009. Fresh mango value chain analysis in Arbaminch area. Organization of value chain competency. Addis Ababa, Ethiopia.

Dereje Birhanu, 2007. Assessment of forest coffee value chains in Ethiopia: A case study in Kafa zone, Gimbo district. Agricultural Science and Resource Management in the Tropics and Subtropics (ARTS).German.

Dunne, A., 2001. Supply chain management: fad, panacea or opportunity? Occasional paper Vol 8(2) 1-40. School of Natural and Rural Systems Management, University of Queensland, Gatton, Queensland, Australia.

ECEX, (2008). Analysis of Coffee Supply, Production, Utilization and Marketing Issues and Challenges in Ethiopia. Understanding Commodities to be Traded at Ethiopia Commodity Exchange, Addis Ababa.

FCA, (2014). Activities, Achievements and Challengs of Ethiopian Cooperatives. Addis Ababa.

Fitter R. and Kaplinsky, , Vol. 32, No. 3, (2001), "Who Gains From Product Rents as The Coffee Market Becomes More Differentiated? A Value Chain Analysis", IDS Bulletin Special Issue on "The Value of Value Chains"

Gereffi, G. (1999a), A Commodity Chains Framework for Analyzing Global Industries. Memo.

Gereffi, G. (1999b), International Trade and Industrial Upgrading in the Apparel Commodity Chain. Journal of International Economics 48 (37-70); Elsevier Science B.V.

Gujarati, Damodar N. (1988). Basic Econometrics. 2nd edition. McGraw-Hill Book Company. New York.

Gujarti, D.N (1998) Basic econometric: MC Graw Hill, New York

Gujarati, D., (1999). Essentials of Econometrics. Second edition, United States Military Academy, West point.

Gujarati, D., 2003. Basic Econometrics. 4th edition. Tata McGraw-Hill Publishing Company Limited, New Delhi, India. $614 \mathrm{p}$.

Hobbs, J., A. Cooney, M. Fulton, 2000. Value market chains in the agri-food sector: What are they? How do they work? Are they for me? Department of Agricultural Economics, University of Saskatchewan,Canada.

Hosmer, D.W. and Lemeshew, S. (1989), Applied Logistic Regression. A Wiley- Inter science Publication, New York.

ICA (International Cooperative alliance), 1995. Cooperatives 'Schools for Democracy - UN Department of public Information, New York.

Issac Paul (2011), an Assessment of the Opportunities and Challenges of The Ethiopian Commodity Exchange. Journal of Sustainable Development in Africa (Volume 13, No.1, 2011), Clarion University of Pennsylvania, Clarion, Pennsylvania

(Jim, D., \& Ruth C., 2006, P5-7). A Value-Chain Approach to Coffee Production: Linking Ethiopian Coffee 
Producers to International Markets. ACDI/VOCA research paper.

Kaplinsky, R. / M. Morris (2000), A Handbook for Value Chain Research, Prepared for the IDRC, Brighton: IDS, online: http://www.ids.ac.uk/ids/global/pdfs/VchNov01.pdf.

Karthikeyan Muthumariappan (2015). Analysis of the Effectiveness of Cooperatives in Coffee Value Chain; Ambo University, Ethiopia.

Kindie Getnet, Shahidur Rashid and Solomon Lemma (2010). Maize Value Chain Potential in Ethiopia, Constraints and opportunities for enhancing the system; International Food Policy Research Institute.

KIT, et al, 2006. Chain empowerment: Supporting African farmers to develop market. Royal Tropical Institute, Amsterdam; Faida Market Link, Arusha; and International Institute of Rural Reconstruction, Nairobi.

Liao, T.F, (1994), Interpreting probability model: Logit, Probit and other generalized model.

Lundy et al., (2002). Value adding, agro enterprise and poverty reduction: a territorial approach for rural business development and rural agro enterprise development project, Colombia.

Maddala, G.S., (2001). Introduction to Econometrics. Third Edition, John Will.

Martin G., et al, (2007). North Houaphanh bamboo value chain analysis. Netherland.

Ministry of Agricultural and Rural Development (MoARD) (2009) ,Sustainable Production and Supply of Fine Arabica Coffee to the World Addis Ababa, Ethiopia

Ministry of Economic Development (MoFED). (2009). Successful Performance in the gricultural Sector, Ethiopia Today: Bi-Monthly Magazine, January. Addis Ababa, Ethiopia.

OCFCU (2009), Oromia Coffee Farmers Cooperative union reports. Reducing Ochratoxin A in Coffee http://www.coffee-ota.org Accessed on Dec. 2012.

Ponte, S., (2002). The late revolution? Regulation, markets and consumption in the global coffee chain. World Development, 30 (7): 1099-1122.

Porter, M., (1985). Competitive advantage: creating and sustaining superior performance. The Free Press, New York.

Pindyck, R.S. and D.L.Rubinfeld (1981), econometric models and economic forecast : second edition, Mc.Graw Hill Book Co., New York.

Schmitz, H., 2005. Value chain analysis for policy makers and practitioners. International Labour Office and Rockefeller Foundation, Geneva, Switzerland.

Schipmann,( 2006),p 13Value Chain Adapted from GTZ, sited as 2012.

Sturgeon J. Timothy (2001), How Do We Define Value Chains and Production Networks. IDS Bulleting, Vol. 32 , No.3. Industrial performance Center, Massachusetts Institute of Technology.

Tirufat Dejene, (2011), Quality and Value Analysis of Ethiopian Coffee Addis Ababa University Mechanical Engineering Department.

UNIDO (United Nations Industrial Development Organization), 2009. Agro-value chain analysis and development: a staff working paper, Vienna.

UNIDO and FAO (United Nations Industrial Development Organization and Food and Agricultural Organization), 2009. Ethiopian agro-industry strategy: Oilseeds value chain analysis, Benchmarking, Strategy and Action Plan , unpublished report.

USAID (United States Agency for International Development), 2011. Value chain analysis of off-season vegetables sub-sector in Nepal. Nepal Economic Agriculture, and Trade Activity. USAID general development office. Kathmandu, Nepal.

World Bank, (2009), World Development Report 2010: Agriculture for Development/World Bank. Vol. 30 Washington, D.C: World Bank.< http://www.worldbank.org >Accessed on April 2018

Appendix 1: Contingency coefficient (CC) of discrete explanatory variables

\begin{tabular}{|c|c|c|c|c|c|c|c|}
\hline No. & Discrete variables & 包 & 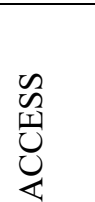 & 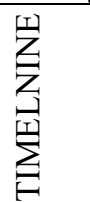 & $\sum_{\substack{i \\
0}}^{\sum_{0}}$ & 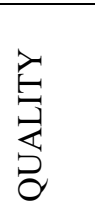 & $\begin{array}{l}\text { N } \\
\text { 蒫 } \\
\underset{\mathbb{Z}}{\mathbb{Z}}\end{array}$ \\
\hline 1 & Corruption & 1.000 & .449 & .000 & .015 & -.520 & -.510 \\
\hline 2 & Access to credit & & 1.000 & .000 & .235 & -.311 & -.453 \\
\hline 3 & Proximity to Cooperative & & & 1.000 & .000 & .000 & .000 \\
\hline 4 & Technology & & & & 1.000 & .051 & -.085 \\
\hline 5 & Training & & & & 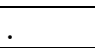 & 1.000 & .259 \\
\hline 6 & Management Capacity & & & & & & 1.000 \\
\hline
\end{tabular}

Source: Computed from survey, 2018 